\title{
Epigenetic Influence of Dam Methylation on Gene Expression and Attachment in Uropathogenic Escherichia coli
}

\author{
Stacy Ann-Marie Stephenson and Paul D. Brown* \\ Department of Basic Medical Sciences, Faculty of Medical Sciences, University of West Indies, Jamaica
}

OPEN ACCESS

Edited by:

Yuji Morita,

Aichi Gakuin University, Japan

Reviewed by:

Paras Jain,

Albert Einstein College of

Medicine, USA

Martin Marinus,

University of Massachusetts, USA

${ }^{*}$ Correspondence:

Paul D. Brown

paul.brown@uwimona.edu.jm

Specialty section: This article was submitted to Infectious Diseases, a section of the journal

Frontiers in Public Health

Received: 04 February 2016 Accepted: 09 June 2016

Published: 27 June 2016

Citation:

Stephenson SA-M and Brown PD (2016) Epigenetic Influence of Dam Methylation on Gene Expression and

Attachment in Uropathogenic Escherichia coli.

Front. Public Health 4:131.

doi: 10.3389/fpubh.2016.00131
Urinary tract infections (UTI) are among the most frequently encountered infections in clinical practice globally. Predominantly a burden among female adults and infants, UTIs primarily caused by uropathogenic Escherichia coli (UPEC) results in high morbidity and fiscal health strains. During pathogenesis, colonization of the urinary tract via fimbrial adhesion to mucosal cells is the most critical point in infection and has been linked to DNA methylation. Furthermore, with continuous exposure to antibiotics as the standard therapeutic strategy, UPEC has evolved to become highly adaptable in circumventing the effect of antimicrobial agents and host defenses. Hence, the need for alternative treatment strategies arises. Since differential DNA methylation is observed as a critical precursor to virulence in various pathogenic bacteria, this body of work sought to assess the influence of the DNA adenine methylase (dam) gene on gene expression and cellular adhesion in UPEC and its potential as a therapeutic target. To monitor the influence of dam on attachment and FQ resistance, selected UPEC dam mutants created via one-step allelic exchange were transformed with cloned qnrA and dam complement plasmid for comparative analysis of growth rate, antimicrobial susceptibility, biofilm formation, gene expression, and mammalian cell attachment. The absence of DNA methylation among dam mutants was apparent. Varying deficiencies in cell growth, antimicrobial resistance and biofilm formation, alongside low-level increases in gene expression (recA and papl), and adherence to HEK-293 and HTB-9 mammalian cells were also detected as a factor of SOS induction to result in increased mutability. Phenotypic characteristics of parental strains were restored in dam complement strains. Dam's vital role in DNA methylation and gene expression in local UPEC isolates was confirmed. Similarly to dam-deficient Enterohemorrhagic E. coli (EHEC), these findings suggest unsuccessful therapeutic use of Dam inhibitors against UPEC or dam-deficient UPEC strains as attenuated live vaccines. However, further investigations are necessary to determine the posttranscriptional influence of dam on the regulatory network of virulence genes central to pathogenesis.

Keywords: dam methylation, uropathogenic Escherichia coli, $\lambda$ red recombineering, gene expression, fluoroquinolone resistance 


\section{INTRODUCTION}

Uropathogenic Escherichia coli (UPEC) is the most ubiquitous pathogen implicated in urinary tract infections (UTIs), accounting for $80-90 \%$ of all infections $(1,2)$. Numerous studies have reported the prevalence of various virulence factors among UPEC isolated from the urinary tract including the adhesins (Type 1, P, S, and F1C fimbriae), toxins (RTX and CNF-1), pore-forming hemolysin, aerobactin, and multiple sideophore-based iron acquisition systems (3-7). Several publications report the existence of these virulence factors in clusters, small virulence cassettes, or large blocks of genes in enteropathogenic, enterohaemorragic, and UPEC strains, not observed in the genome of fecal isolates $(3,8-14)$. These factors are often linked or co-regulated, acting in concert according to host response and environmental signals (15). Such features contribute to the adherence, colonization, multiplicity, propagation, and persistence of UPEC strains within the mammalian host's urinary tract, despite hydrodynamic challenges encountered (16).

The adhesion of UPEC to mucosal cells is the most vital step for the initiation of UTI and is mediated by P and Type 1 fimbriae, binding to digalactoside-containing globoseries glycosphingolipids and mono D-mannose residues, respectively (17-21). However, this report focuses on the vastly studied, mannose-resistant pap (pyelonephritis-associated pili) fimbriae by which genotypic studies have identified the gene in approximately $80 \%$ of $E$. coli isolates that cause pyelonephritis (15). The pap operon mainly consists of fimbriae structural subunits (papA, -C, -D, -E, -F, -G); subunit to terminate fimbrial growth and anchor mature fimbriae to host cell surface, $p a p \mathrm{H}$; and the divergently encoded regulatory genes pap $\mathrm{B}$ and $p a p \mathrm{I}$, within which the main promoter is located. Expression of these promoters is dependent on the methylation status of the two GATC sites within the intergenic region (19, 22). Although there are reports that support fimbriae-mediated UPEC adherence in vitro $(7,23,24)$, the significance of $P$ fimbriae for infectivity has not been confirmed as only subtle adherence roles were exhibited in uroepithelial cell culture models (25).

DNA methylation is a vital epigenetic, postreplicative alteration that is catalyzed by a class of enzymes referred to as the DNA methyltransferases (MTases). Crucial to the regulation of many cellular processes in eukaryotes and prokaryotes, DNA adenine methylase (Dam) plays numerous roles in DNA mismatch repair, transcriptional regulation, and SOS response stimulation as part of the cell cycle (26-30). In E. coli, the Dam enzyme catalyzes the postreplicative transfer of methyl from $S$-adenosyl-L-methionine to the N-6 position of adenine in the tetranucleotide GATC sequence in hemimethylated DNA $(28,31-34)$. Conserved for the manifestation of virulent genes, Dam's essential function in pathogenesis has also been reported in several bacterial species including E. coli, Salmonella enterica serovar Typhimurium, Yersinia spp., Haemophilus influenzae, Vibrio cholera, and Pasterella multocidas $(28,31,32,35)$. The presence of GATC sites in the -10 and -35 hexamers of promotor regions, directly affecting gene expression by regulating the binding of transcriptional factors or RNA polymerase according to methylation state at the sites, serves to substantiate this phenomenon.
Though not essential to the viability of $E$. coli, Dam's involvement in transcriptional modulation was first proven through detailed studies of pap operon encoding pili necessary for UTI in $\operatorname{UPEC}(26,28,31,33,35-40)$. The pap pili-mediating adhesion of UPEC to mammalian uroepithelial cells is epigenetically regulated through methylation at the intergenic region of pap IB to produce "ON/OFF" phase variation (expression or nonexpression, respectively) by individual cells $(30,34,38,41)$. The phase variation mechanism via Dam methylation pattern acts a switch for the expression of the operon and confirms reports for the significance of Lrp, PapI, and Dam as transcription regulators $(28,31,34,38,42,43)$. The reversible expression of pap is theorized to allow the bacteria to attach and detach from the urogenital tissues, which in turn enables colonization and infection (33).

Previous research indicates Dam-deficient $\left(\mathrm{Dam}^{-}\right)$mutants of pathogenic Salmonella serovar Typhimurium being rendered avirulent with the overexpression of over 35 genes (44) and downregulation of others, preferentially expressed during infection. This was made evident by Badie et al. (36) signifying amplified defects in the gene expression of virulence genes for flagellin synthesis, motility, and bile resistance in pathogenic Salmonella strain 14028 (34). To date, studies centered on the modulation of responses in the host immune system to attenuated Salmonella Dam-serovars have indicated that greater immunity is conferred to vaccinated hosts (36) and may be highly effective as live vaccines against murine typhoid fever in an increased attenuated state $(33,45)$ taking in consideration the persistence of Dam mutants in infected animals (46).

In contrast, Dam ${ }^{-}$mutants of E. coli have demonstrated increased expression for numerous genes including sulA, $\operatorname{trpS}$, $\operatorname{trpR}$, tyrR, and $g \ln \mathrm{S}$, within which GATC sites are localized within the -10 and -35 region of their promoters $(34,47)$. Likewise, the increased adherence and actin pedestal formation on cultured mammalian cell lines for $\Delta$ dam mutants of Enterohemorrhagic E. coli (EHEC) OH157:O7 when compared to wild type strains speaks to the epigenetic effect of dam on various bacterial species (26). Within this milieu, this study was conducted to determine the epigenetic influence of dam on growth, fluoroquinolone resistance, gene expression, and human uroepithelial cell attachment in UPEC by the employment of lambda $(\lambda)$ red recombineering.

\section{MATERIALS AND METHODS}

\section{Bacterial Strains, Growth Conditions, and Culture Medium}

A total of 174 non-duplicate uropathogenic fluoroquinoloneresistant E. coli strains isolated from patients diagnosed with uncomplicated UTI were analyzed prior to epigenetic studies $(48,49)$. Uropathogenic control strain E. coli CFT073 [genotype $a m p^{\mathrm{R}-}, \mathrm{dam}^{+}, \mathrm{MDR}^{-}, q n r \mathrm{~A}^{-}, \mathrm{QRDR}^{-}$, pap $\left.\mathrm{EF}^{+}\right]$(50) and fluoroquinolone-resistant $q n r \mathrm{~A}^{-}$, and cured quinolone-resistance determining region (QRDR)-positive E. coli clinical isolates A620b, C119, U155 [genotype $a m p^{\mathrm{R}-}, \mathrm{dam}^{+}, \mathrm{MDR}^{+}, q n r \mathrm{~A}^{-}$, $\mathrm{QRDR}^{+}$, pap $\left.\mathrm{EF}^{+}\right]$(48) were utilized for epigenetic studies. Fluoroquinolone-resistant qnr-positive control strains $E$. coli strain Lo QnrA ${ }^{+}$and E. coli J53 pMG252 were generously donated 
by Dr. G. A. Jacoby and Prof. P. Nordmann, respectively. E. coli ATCC 25922 and MG1655, non-pathogenic negative controls used were generously provided by the Microbiology Department at the University Hospital of the West Indies (UHWI), Mona, Jamaica and the University of Minnesota, respectively. Multidrugsusceptible uropathogenic E. coli CFT073 [WAM2267] and J53 $A z^{\mathrm{R}}$ served as control strains in antibiotic susceptibility and Dam methylation studies (ATCC, VA, USA). In addition, the laboratory E. coli strain MG1655 and JM109 [genotype K-12sp recA-, end $\left.\mathrm{A}^{-}, \mathrm{F}^{\prime}\right]$ (Promega, WI, USA) were utilized as dam-positive control and competency for cloning, respectively. All isolates were routinely cultured in either Luria-Bertani (LB) medium (Difco $^{\text {TM }}$, BD Diagnostics, MD, USA) or Tryptic Soy agar (EMD Millipore, Merck, Darmstadt, Germany) supplemented with antibiotics including ampicillin $(100 \mu \mathrm{g} / \mathrm{ml})$, carbenicillin $(125 \mu \mathrm{g} /$ $\mathrm{ml})$, chloramphenicol $(10$ or $15 \mu \mathrm{g} / \mathrm{ml})$, ciprofloxacin $(1 \mu \mathrm{g} / \mathrm{ml})$, and nalidixic acid $(40 \mu \mathrm{g} / \mathrm{ml})$ (Cellgro ${ }^{\circledR}$, Mediatech Inc., VA, USA or Sigma-Aldrich, MO, USA), where appropriate. When performing genetic transformations, the Super Optimal Broth (SOB) medium (AMRESCO, OH, USA) served as a nutrient-rich medium for the resuscitation of cells. All strains were incubated at $37^{\circ} \mathrm{C}$ unless indicated otherwise.

\section{Plasmids}

Plasmids utilized were: (a) temperature-sensitive helper plasmid pKM208 (8731 bp) that harbors $\lambda$ red genes including bet, gam and exo and $a m p^{\mathrm{R}}$ gene under the control of $\mathrm{P}_{\text {tac }}$ promoter and lacI repressor (51); (b) pKD3 (2804 bp) (Genbank AY048742) to obtain the chloramphenicol acetyl transferase gene template required for linear DNA preparation for recombineering experiments (52); (c) cloning plasmid pGEM $^{\circledR}-\mathrm{T}$ Easy Vector (3015 bp) that encodes the $a m p^{\mathrm{R}}$ gene (Promega, WI, USA) or
pCR ${ }^{\circledR} \mathrm{II}-\mathrm{TOPO}(4.0 \mathrm{~kb})$ and $a m p^{\mathrm{R}}+k a n^{\mathrm{R}}$ conferring ampicillin and kanamycin resistance (Invitrogen, CA, USA), respectively.

\section{DNA Manipulations}

\section{Dam Screening}

Prior to determining the putative influence of the dam gene on the P fimbriae attachment and quinolone resistance among fluoroquinolone-susceptible and -resistant UPEC, strains were subjected to screening for dam. UPEC isolates were subjected to genomic DNA extraction using the Promega Wizard Genomic DNA Extraction kit (Promega, WI, USA) according to the manufacturer's instructions. DNA extracts were quantified using the Thermoscientific Nanodrop 2000 Spectrophotometer (Wilmington, DE, USA) followed by dam amplification by PCR using Promega GoTaq Green 2× kit (Promega, WI, USA), $1 \mu \mathrm{l}$ DNA and the UR427/UR428 primer pair (Table 1) to produce an amplicon size of $1071 \mathrm{bp}$. Forward primer UR427 was located upstream the dam gene while UR428 was located further downstream. As a foundation for primer design, E. coli laboratory strain K-12 substrain MG1655 (53) was used to augment the 837 bp dam gene and flanking regions. PCR reactions were performed using the GeneAmp 9700 Thermal Cycler (Applied Biosystems, USA) according to the following parameters: $95^{\circ} \mathrm{C}$ for $5 \mathrm{~min}$ (initial denaturation), 29 cycles of $95^{\circ} \mathrm{C}$ for $30 \mathrm{~s}, 55^{\circ} \mathrm{C}$ for $30 \mathrm{~s}$, $72^{\circ} \mathrm{C}$ for $1 \mathrm{~min}$, and $72^{\circ} \mathrm{C}$ for $10 \mathrm{~min}$ (final extension). Amplicons were detected by UV fluorescence following electrophoresis in ethidium bromide-stained agarose gels.

\section{DNA Methylation Assay}

Chromosomal and plasmid DNA from dam-positive E. coli isolates A620b, cured C119 (cC119), U155, uropathogenic E. coli CFT073 and dam-positive control strain E. coli MG1655

TABLE 1 | Primers, sequence, and amplicons size used in epigenetic influence of Dam studies.

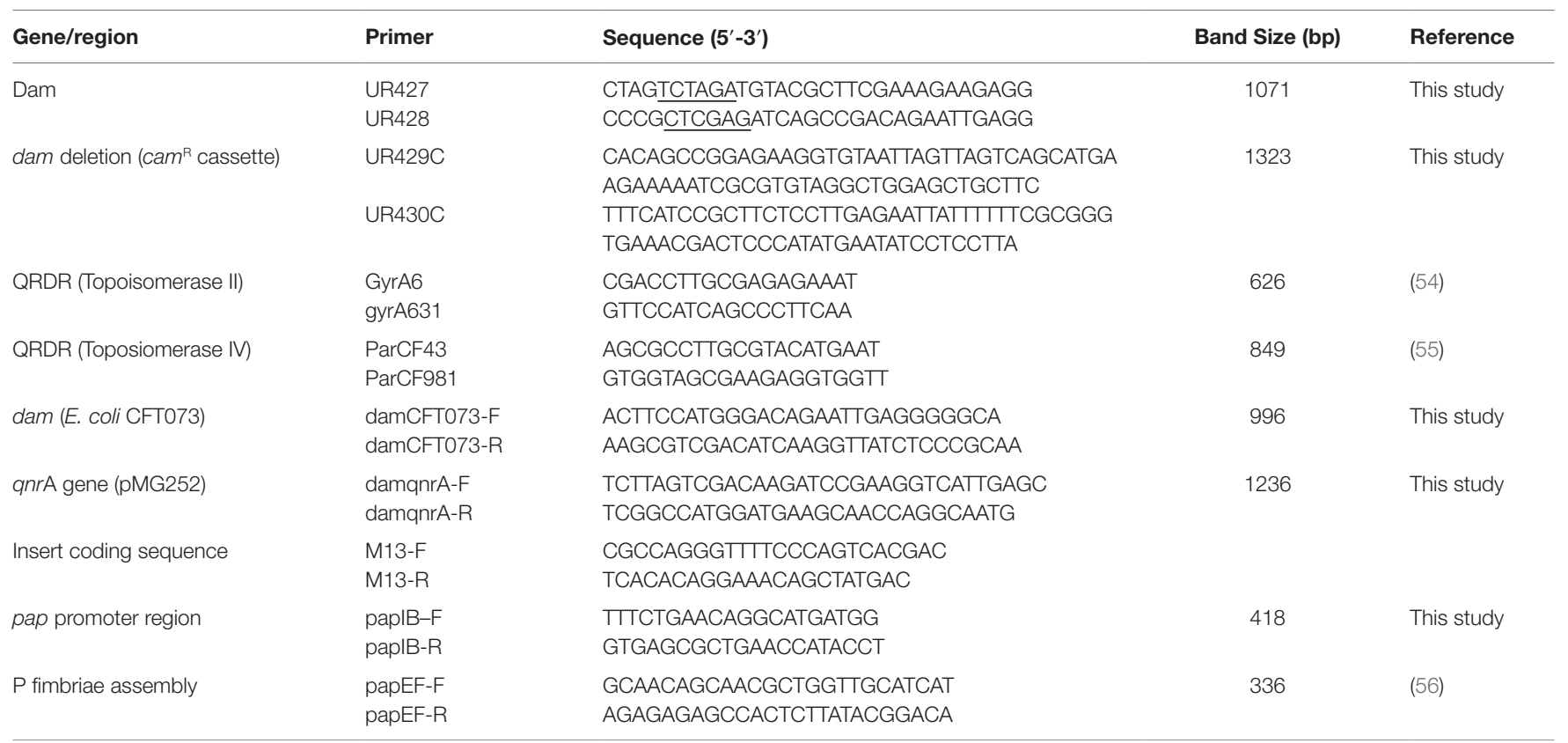

UR427 - Xbal restriction enzyme site.

UR428 - Xhol restriction enzyme site. 
TABLE 2 | Primers, sequence, and amplicons size used in epigenetic influence of Dam studies (continued).

\begin{tabular}{|c|c|c|c|c|}
\hline Gene/region & Primer & Sequence $\left(5^{\prime}-3^{\prime}\right)$ & Amplicon size (bp) & Reference \\
\hline Aerobic respiration control protein & $\begin{array}{l}\operatorname{arcA-F} \\
\operatorname{arcA-R}\end{array}$ & $\begin{array}{l}\text { GAAGACGAGTTGGTAACACG } \\
\text { CTTCCAGATCACCGCAGAAGC }\end{array}$ & 645 & $(57)$ \\
\hline DNA gyrase subunit B & $\begin{array}{l}\text { gyrB-F } \\
\text { gyrB-R }\end{array}$ & $\begin{array}{l}\text { TCGGCGACACGGATGACGGC } \\
\text { ATCAGGCCTTCACGCGCATC }\end{array}$ & 911 & (58) \\
\hline Malate dehydrogenase & $\begin{array}{l}\text { mdh-F } \\
\text { mdh-R }\end{array}$ & $\begin{array}{l}\text { ATGAAAGTCGCAGTCCTCGGCGCTGCTGGCGG } \\
\text { TTAACGAACTCCTGCCCCAGAGCGATATCTICTT }\end{array}$ & 932 & (58) \\
\hline ATP/GTP-binding motif & $\begin{array}{l}\text { recA-F } \\
\text { recA-R }\end{array}$ & $\begin{array}{l}\text { CGCATTCGCTITACCCTGACC } \\
\text { TCGTCGAAATCTACGGACCGGA }\end{array}$ & 780 & (58) \\
\hline Transcription factor sigma S & $\begin{array}{l}\text { rpos-F } \\
\text { rpoS-R }\end{array}$ & $\begin{array}{l}\text { TATGAGTCAGAATACGCTGAAA } \\
\text { GGAACAGCGCTTCGATATTCAG }\end{array}$ & Varies & (59) \\
\hline Quinolone-resistance gene & $\begin{array}{l}\text { qurA-F } \\
\text { qurA-R }\end{array}$ & $\begin{array}{l}\text { ATाTCTCACGCCAGGATTTG } \\
\text { GATCGGCAAAGGTTAGGTCA }\end{array}$ & 516 & $(60)$ \\
\hline
\end{tabular}

were subjected to differential digestion for dam function with restriction endonucleases Sau3AI, MboI, and DpnI according to Chen et al. (61) with modifications. Essentially, $0.5 \mu \mathrm{g}$ of chromosomal and plasmid DNA was digested for $1.5 \mathrm{~h}$ at $37^{\circ} \mathrm{C}$ with $2 \mathrm{U}$ Sau3AI (Promega, WI, USA), 10 U DpnI (New England Biolabs, MA, USA), or 2.5 U MboI. Sau3AI cleaves DNA at GATC sites regardless of methylation state, $D p n I$ cleaves GATC sites that have a methylated adenine residue, and $M b o$ I cleaves unmethylated GATC sites. The resulting DNA was visualized under UV on ethidium bromide-stained agarose gels.

\section{Dam Mutant Construction}

dam deletion mutants were created via the $\lambda$ red recombinase system involving a modified one-step allelic exchange and inactivation protocol as proposed by Datsenko and Wanner (52) and illustrated in Figure 1A. Clinical and control UPEC strains containing the Red recombinase helper plasmid pKM208 were generated following electroporation using the BIORAD Gene Pulser X-cell Electroporation System $(2 \mathrm{kV}, 25 \mu \mathrm{FD}$, and $200 \Omega)$. After recovery of cells in SOC medium (Invitrogen, CA, USA) at $37^{\circ} \mathrm{C}$ for $1 \mathrm{~h}, 100 \mu \mathrm{l}$ of the electroporation mixture was plated in triplicate on LB agar with $125 \mu \mathrm{g} / \mathrm{ml}$ carbenicillin and incubated overnight with agitation at $30^{\circ} \mathrm{C}$ to maintain the replication of the temperature-sensitive pKM208 within the cells.

To construct the DNA fragment to be used for allelic exchange to make the dam deletion mutation, PCR amplification of the chloramphenicol cassette $\left(\mathrm{cam}^{\mathrm{R}}\right)$ was conducted using the $\mathrm{pKD} 3$ template (52) and the dam insertion primer pair UR429C/UR430C. Each primer carried extra sequence overhangs of 50 bp genome homology to either the $5^{\prime}$ end (UR429C) or $3^{\prime}$ end (UR430C) of the dam gene, followed by approximately $20 \mathrm{bp}$ sequence homology to the chloramphenicol resistance gene $\left(\mathrm{cam}^{\mathrm{R}}\right)$ to generate an amplicon that inserted the resistance gene roughly $50 \mathrm{bp}$ into the coding sequence of the dam gene ( $\Delta$ dam: $\mathrm{cam}^{\mathrm{R}}$ fragment). PCR parameters included initial denaturation at $95^{\circ} \mathrm{C}$ for $5 \mathrm{~min}, 29$ cycles of $95^{\circ} \mathrm{C}$ for $30 \mathrm{~s}, 55^{\circ} \mathrm{C}$ for $30 \mathrm{~s}$ and $72^{\circ} \mathrm{C}$ for $1 \mathrm{~min} 30 \mathrm{~s}$, and final extension at $72^{\circ} \mathrm{C}$ for $10 \mathrm{~min}$. Following electrophoresis, the 1113 bp band was purified by gel extraction by the QIAquick Gel Extraction kit (QIAGEN Sciences Inc., MD, USA) according to the manufacturer's instructions in a final volume of $50 \mu \mathrm{l}$ water and quantitated as previously described.
Electrocompetent suspensions of IPTG-induced (1 $\mathrm{mM})$ E. coli strains A620b, cC119, U155, and CFT073 (all harboring pKM208) were electroporated with $5 \mu \mathrm{l}$ of purified $\Delta$ dam:cam ${ }^{\mathrm{R}}$ PCR product and recovered in SOC medium. Recombinant clones were selected on LB agar supplemented with $10 \mu \mathrm{g} / \mathrm{ml}$ chloramphenicol and incubated at $37^{\circ} \mathrm{C}$. To facilitate the loss of pKM208 from carbenicillin-resistant transformants, previously screened transformants were plated on medium with $10 \mu \mathrm{g} / \mathrm{ml}$ chloramphenicol and incubated at $42^{\circ} \mathrm{C}$ overnight. Recombinant clones were verified by plating on medium containing the appropriate antibiotic for incubation at $37^{\circ} \mathrm{C}$. Selected strains were chloramphenicol resistant and carbenicillin sensitive. Presumptive colonies were further confirmed for the presence of the $\Delta$ dam: cam $^{\mathrm{R}}$ allele (1323 bp) by PCR using primers UR427/ UR428 as previously described prior to dam methylation assays and observations under the light microscope (WARDS Natural Science Establishment, Inc., NY, USA).

\section{Complementation of Dam and damqnrA}

Complementation vectors pGEMdam or pGEMQA were constructed by inserting the dam and qnrA genes amplified from E. coli CFT073 and C119 wild-type, respectively, into Promega pGEM $^{\circledR}$-T Easy vector system (Promega, WI, USA) according to the manufacturer's recommendations. PCR amplification was conducted individually using the corresponding laboratorydesigned primer pairs damCFT073-F/damCFT073-R and damqnrA-F/damqnrA-R (Table 1) under parameters suitable for selected sequence. The DNA band of interest was excised and gel purified (IBI Scientific, KappCourt, IA, USA) followed by cloning in pGEMdam or pGEMQA according to the Promega pGEM $^{\circledR}-\mathrm{T}$ Easy vector system. Subsequently, presumptive colonies were screened by PCR, subjected to genomic and plasmid DNA extraction and quantification as previously described. Complement strains were further tested for dam function by the Dam methylation assay and visualized under the light microscope (WARDS Natural Science Establishment, Inc., NY, USA).

\section{Growth Rate Studies}

To investigate the impact of dam on UPEC growth rate, wild-type (CFT073), cured parental (C119), $\Delta$ dam and complement $\Delta d a m$ strains of E. coli CFT073 and C119 were grown to saturation 

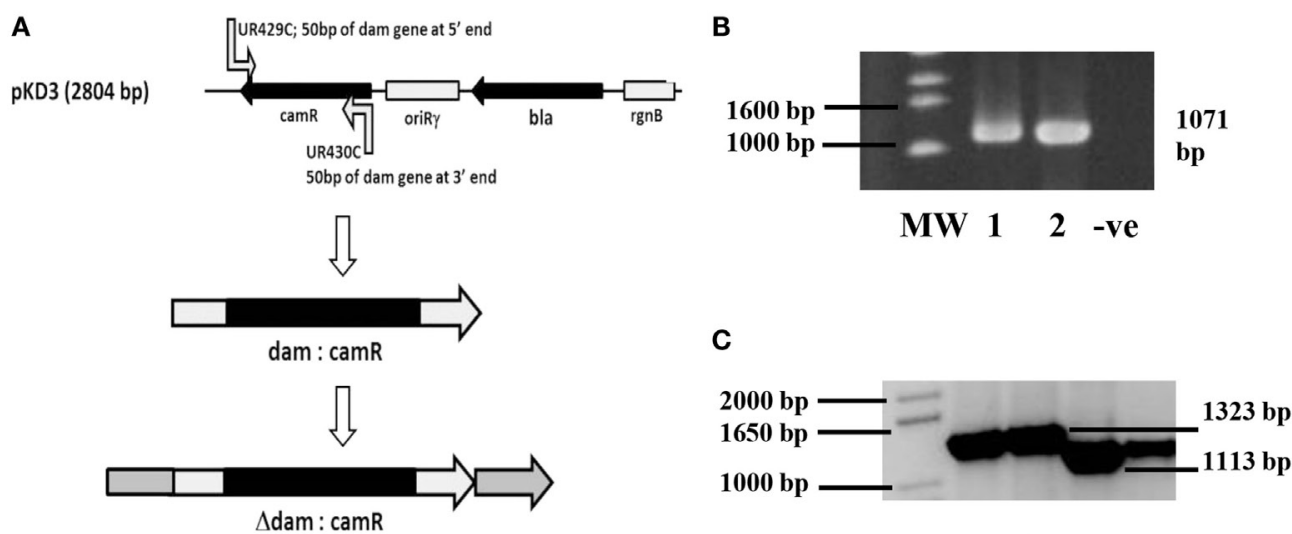

$\begin{array}{llll}\text { MW } 1 & 2 & 3 & 4\end{array}$

D

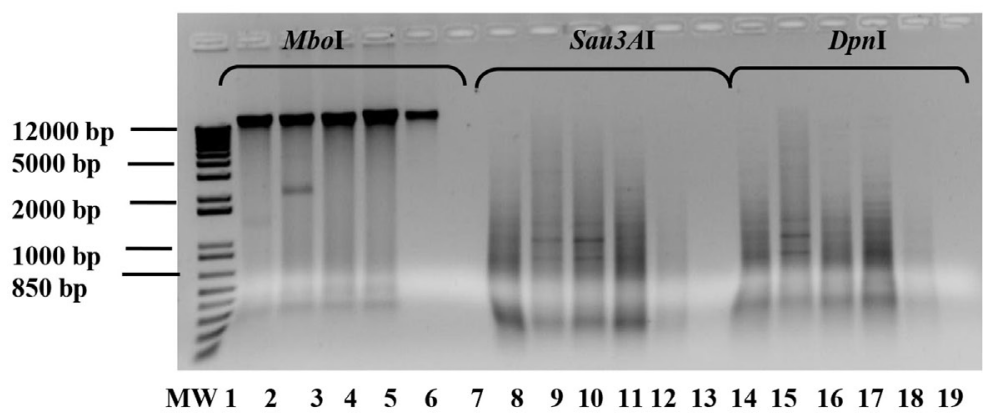

E

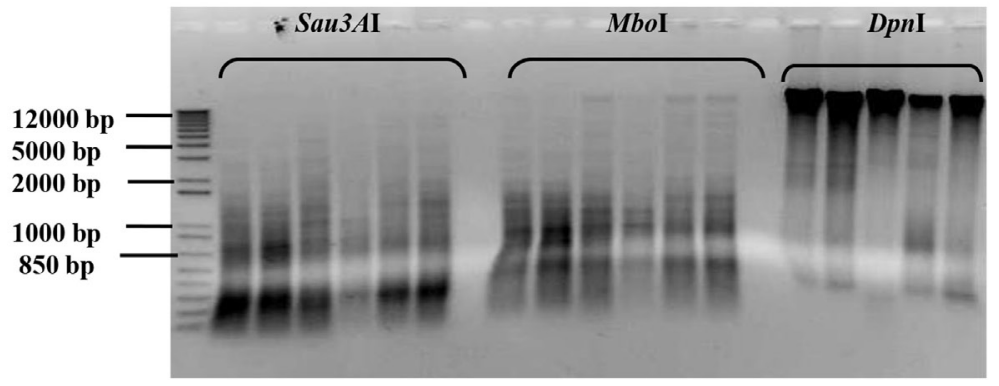

$\begin{array}{lllllllllllllllllll}\text { MW } 1 & 2 & 3 & 4 & 5 & 6 & 7 & 8 & 9 & 10 & 11 & 12 & 13 & 14 & 15 & 16 & 17 & 18 & 19\end{array}$

$\mathbf{F}$

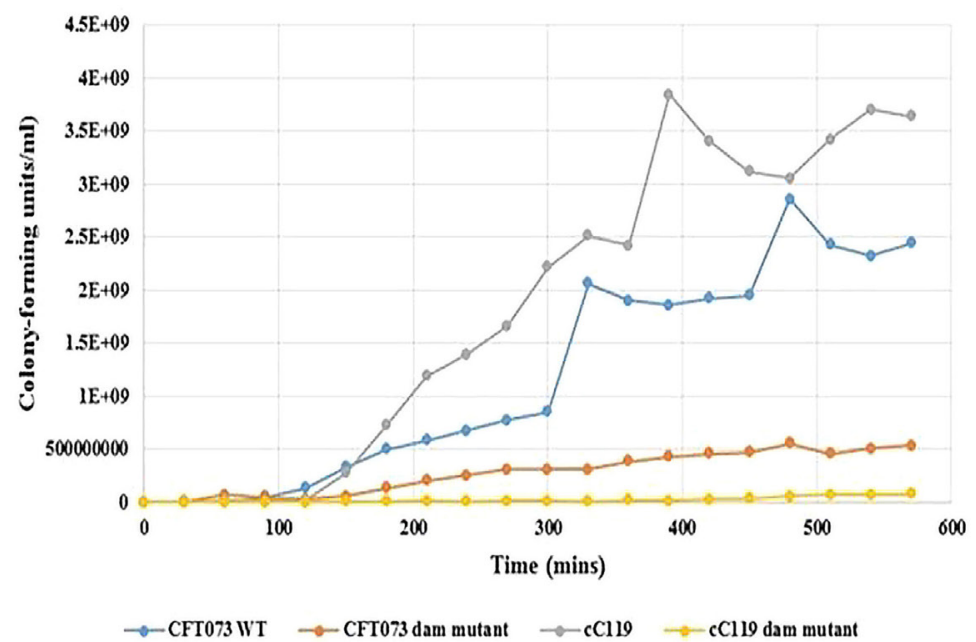

FIGURE 1 | Genotypic and growth characteristics displayed by parental and dam-mutant strains of UPEC. 
FIGURE 1 | Continued

(A) Schematic diagram of gene disruption strategy for chromosomal insertion of chloramphenicol resistance gene from pKD3 into dam gene within UPEC chromosome subsequent to $\lambda$ red recombineering with pKM208. (B) Amplified dam fragment from wild type UPEC strains CFT073 (lane 1) and cured parental strains C119 (lane 2) to produce 1071 bp amplicon. MW is 1 kb DNA ladder (Bioneer Corporation, Republic of Korea) and -ve is negative control. (C) PCR screening of UPEC candidates for dam mutation observed as 1323 bp products using primers UR427 and UR428. MW is a $1 \mathrm{~kb}$ Plus DNA ladder (Invitrogen, USA). (D) Dam methylation pattern in UPEC CFT073 wild type (lanes 1, 2, 8, 9, 14, 15), C119 wild type (lanes 3, 4, 10, 11, 16, 17), and E. coli K-12 substrain MG1655 $(5,12,18)$ strains subsequent to digestion with Mbol, Sau3Al, and Dpnl. The negative control (7, 13, 19) and $1 \mathrm{~kb}$ Plus DNA ladder (MW) are also shown. (E) Dam methylation pattern in UPEC dam mutants CFTO73 (lanes 1, 2, 3, 8, 9, 10, 15, 16, 17) and C119 wild-type (lanes 4, 5, 6, 11, 12, 13, 18, 19) subsequent to digestion with Sau3Al, Mbol, and Dpnl. The negative control (lanes 7, 14) and $1 \mathrm{~kb}$ Plus DNA ladder (MW) are also shown. (F) Growth curve (CFU/milliliter versus time) for UPEC strains CFT073, CFT073 $\Delta$ dam, cC119, and cC119 $\Delta$ dam.

in LB with appropriate antibiotics at $37^{\circ} \mathrm{C}$, the growth rate measured by UV/Vis spectrophotometer (Cecil CE 9000 series, Cecil Instruments Limited, Cambridge, UK) and viable cell count method according to a modified protocol by Matlock et al. (62). A $2 \%$ batch culture was prepared by transferring $2 \mathrm{ml}$ of an overnight culture in $100 \mathrm{ml}$. The culture was grown for up to $10 \mathrm{~h}$, during which the optical density at $600 \mathrm{~nm}$ and associated viable cell count (CFU/milliliter) was determined following duplicate plating on LB agar incubated overnight at $37^{\circ} \mathrm{C}$. Results were obtained from three separate experiments. Growth rate $(k)$ was calculated as:

$$
k=\frac{\log 10\left[X_{t}\right]-\log 10\left[X_{0}\right]}{0.301 \times t}=\mathrm{gen} / \mathrm{h}
$$

where $X_{\mathrm{t}}$ is the higher CFU/milliliter, $X_{0}$ is the lower CFU/ milliliter, and $t$ is the time interval between both (in hours).

Generation time $\left(t_{\mathrm{gen}}\right)$ was calculated as:

$$
\mathrm{t}_{(\mathrm{gen})}=1 / k=\mathrm{h} / \text { gen }
$$

\section{Antimicrobial Susceptibility}

Wild-type and $\Delta$ dam-mutant strains of E. coli CFT073 and cured C119 as well as control strains E. coli strain Lo QnrA ${ }^{+}$and E. coli JM109 harboring PGEMQA were subjected to antimicrobial susceptibility testing using Sensititre Substrate-in-Well GNUR2F Gram-negative MIC plates (TREK Diagnostic Systems, Inc., OH, USA) for inoculation and incubation (63). A $50 \mu \mathrm{l}$ suspension of the sample was used to inoculate Sensititre plates, sealed and incubated at $35^{\circ} \mathrm{C}$ for $18-24 \mathrm{~h}$. The plates were observed for the presence of a growth button at the base of the microtiter well and fluorescence intensity ( +++ to 0 ) captured with a UV Benchtop Variable Transilluminator and Photo Doc-It Imaging System (UVP, CA, USA).

\section{Biofilm Analysis}

The correlation of dam with oxygen and antiobiotic pressure on the formation of biofilms in the presence and absence of 2\% D-mannose (AMRESCO, OH, USA) were explored. First, overnight cultures of bacterial strains were diluted 1:10 into Mueller-Hinton broth, $0.2 \mathrm{ml}$ transferred into 96-well polystyrene microtiter plates (Nunc-Immuno Microwell) and incubated at $37^{\circ} \mathrm{C}$ for $24 \mathrm{~h}$ without agitation. Oxidative stress studies were initiated by the addition of hydrogen peroxide $\left(\mathrm{H}_{2} \mathrm{O}_{2}\right)$ to microwell cultures to a final concentration of $0,0.1,0.2,0.3,1$, or $2 \mathrm{mM}$, prior to incubation and processing as indicated by a modification to concentrations utilized by Hedge et al. (64) and
Hryckowian et al. (65). Likewise, for the effect of the antimicrobial agents, the quinolones, nalidixic acid $(0,8,24,32,40$, or $48 \mu \mathrm{g} / \mathrm{ml})$, and ciprofloxacin $(0,1,2,3,4$, or $5 \mu \mathrm{g} / \mathrm{ml})$ were added to microwell cultures prior to incubation. Post $24 \mathrm{~h}$ incubation, wells were decanted, washed thrice with $1 \times$ phosphate-buffered saline (PBS, pH 7.4), and adhered bacterial cells stained with $200 \mu \mathrm{l} 0.1 \%$ crystal violet for $15 \mathrm{~min}$ at room temperature. Unbound dye was decanted, wells washed thrice, and dried. Stained cells were dissolved with 95\% ethanol for $15 \mathrm{~min}$, and optical density measured at $570 \mathrm{~nm}$ using Victor X Multilabel Plate Reader (PerkinElmer, MA, USA). All experiments were conducted in triplicate from three independent experiments (20). Statistical data analysis was conducted using the Student's $t$ test for variance in data collected from test strains when compared to parental or wild type (SPSS software, Version 20, SPSS Inc., USA). A $p$ value of $<0.05$ was considered statistically significant.

\section{Transcriptional Analysis}

In order to determine the impact of dam on DNA transcription, cured parental, dam mutant and complement strains of C119 and CFT073 were cultured overnight then subjected to RNA isolation and purification using the Promega SV RNA Isolation Kit (Promega, WI, USA) according to the manufacturer's instructions. Reverse Transcription was conducted using the GoScript ${ }^{\mathrm{TM}}$ Reverse Transcriptase System First-Strand Synthesis System (Promega, WI, USA) to synthesize first-strand cDNA as instructed by the manufacturer. cDNA was amplified by means of semi-quantitative PCR (sq-PCR) for dam, papIB, papEF, $q n r \mathrm{~A}$, and the housekeeping genes $(\operatorname{arc} \mathrm{A}, g y r \mathrm{~B}, m d h$, recA, and rpoS) expression in E. coli $\mathrm{C} 119$ and CFT073 parental, mutant, and complement strains using GoTaq ${ }^{\circledR}$ Green Reaction Mix and gene-specific primers (Tables 1 and 2), annealed at $55^{\circ} \mathrm{C}$ for $1 \mathrm{~min}$. Ten microliter samples were taken at cycles $23,25,30$, and electrophoresed in ethidium bromide-stained agarose gels (66).

\section{Phenotypic Influence of Dam Methylation on P Fimbriae}

The papI-B pili regulatory region was identified using the papIP1for/papIP1rev primers as described by Holden et al. (67). The concentrated, purified 418-bp PCR product of the papI-B regulatory region from strains $\mathrm{U} 155$ and $\mathrm{C} 119(\sim 1.8 \mathrm{ng}$ in $3.5 \mu \mathrm{l})$ was cloned into Invitrogen $\mathrm{pCRII}^{\circledR}$ TOPO vector (Invitrogen, CA, USA) according the manufacturer's instructions to construct pSAMS1 and pSAMS2, respectively, further used to transform One Shot E. coli competent cells (Invitrogen, CA, 
USA). Transformants were selected on LB supplemented with $50 \mu \mathrm{g} / \mathrm{ml}$ carbenicillin $/ 40 \mathrm{mg} / \mathrm{ml} \mathrm{X-gal} / 100 \mathrm{mM}$ IPTG, prior to recombinant vector purification by QIAprep Spin Miniprep kit (QIAGEN Inc., CA, USA). The cloned pap intergenic DNA insert was confirmed by colony PCR with M13F/M13R primers, sequenced at the Virginia Commonwealth University Core Facility in Richmond, VA, USA and analyzed using NCBI BLAST. dam methylation of the papI-papB insert was determined as previously described in the Materials and Methods prior to pSAMS digestion by EcoRI (Promega, WI, USA) to release the intergenic region.

\section{papl Expression Assay}

In order to determine variation in papI expression, wild-type and dam-mutant strains of $\mathrm{cC} 119$ and CFT073 were cultured overnight then subjected to RNA isolation and RT-PCR using the QIAGEN RNeasy Mini kit, Invitrogen Superscript ${ }^{\mathrm{TM}}$ First-Strand Synthesis System (Invitrogen, CA, USA), respectively according to the manufacturer's instructions. cDNA templates were amplified by means of semi-quantitative PCR using papICFT0731F/papICFT073-1R primers (Table 1) as described by Holden et al. (67). Ten microliter aliquots were processed as previously noted.

\section{Attachment Assays}

Urinary human cell lines, HEK-293 (human embryonic kidney cells) and HTB-9 (human bladder cells) (ATCC, VA, USA) were individually cultured in $25-\mathrm{cm}^{2}$ flasks prior to washing attached cells with $10 \mathrm{ml}$ Dulbecco's phosphate-buffered saline (D-PBS) before trypsin (ATCC) exposure. Cells were incubated for $10 \mathrm{~min}$ at room temperature until the monolayer was almost detached, followed by the addition of $9 \mathrm{ml}$ minimal essential media (MEM) with $10 \%$ fetal calf serum (ATCC) and amino acids (Cellgro ${ }^{\circledR}$ ), and RPMI-1640 media with glucose, HEPES and 10\% fetal calf serum for HEK-293 cells and HTB-9 cells, respectively. Cells and suitable medium (1:1) were added in duplicates to six-well cell culture plates following 1:4 areal dilution and incubated at $37^{\circ} \mathrm{C}$ in $5 \% \mathrm{CO}_{2}$ for $48 \mathrm{~h}$ until confluent. One set of cell culture plates was utilized for assessment of total E. coli cells present, and the other for assessment of adherent $E$. coli cells only. Simultaneously, E. coli control, cured parental, and dam-mutant strains of C119 and CFT073 were cultured in LB without shaking for $48 \mathrm{~h}$. Prior to the attachment assay, MEM (HEK-293 cells) and RPMI-1640 (HTB-9 cells) were aspirated from the wells and $1 \mathrm{ml}$ of the appropriate medium supplemented with 20\% (1.1M) D-mannose (Sigma-Aldrich) added to each well. Furthermore, $10 \mu \mathrm{l}$ bacterial culture $(\mathrm{OD}=1$ at $600 \mathrm{~nm}$ ) mixed with $1.8 \mu \mathrm{l}$ of $20 \% \mathrm{D}$-mannose was added to each well. Samples were evenly distributed, centrifuged for $5 \mathrm{~min}$ at $600 \times \mathrm{g}$, and incubated at $37^{\circ} \mathrm{C}$ in $5 \% \mathrm{CO}_{2}$ for $1.5 \mathrm{~h}$. At the end of incubation, plates designated for the detection of adherent $E$. coli cells were washed five times with Dulbecco's PBS with $1 \mathrm{mM} \mathrm{CaCl}_{2}$ and $0.5 \mathrm{mM} \mathrm{MgCl}_{2}\left(\mathrm{PBS}^{2+}\right), 40 \mu$ Triton $\mathrm{X}-100$ added to lyse the cells, and the bottom of wells scraped. Sterile $\mathrm{PBS}^{2+}$ was added to the wells and mixed before serially diluting to $10^{4}\left(100 \mu \mathrm{l}\right.$ sample to $\left.900 \mu \mathrm{l} \mathrm{PBS}^{2+}\right)$ for plating on LB agar. In contrast, plates selected for the determination of total number of bacteria were not subjected to washing but direct treatment with Triton-X, scraping, serial dilution and plating on $\mathrm{LB}$ agar. All plates were incubated overnight at $37^{\circ} \mathrm{C}$, and $\mathrm{CFU} /$ milliliter determined and analyzed.

\section{RESULTS}

\section{Dam Methylation Pattern, Growth Rate and Phenotypic Characteristics of UPEC Dam Mutants}

Of the 174 FQ-R resistant isolates including cured UPEC strains A620b, C119, U155, CFT073, and MG1655 screened, $71 \%$ were positive for the dam sequence amplified by UR427/ UR428 to produce a 1071 bp product (Figure 1B). Chromosomal digestion of parental UPEC strains cC119 and CFT073 with methylation-sensitive enzymes ( $D p n \mathrm{I}$ and $\mathrm{MboI}$ ) revealed the presence of functional dam capable of GATC methylation within wild-type strains (Figure 1D). To assess the putative role of dam on virulence, dam-deficient mutant strains were successfully constructed using Red-recombinase-mediated allelic exchange as the wild-type dam gene was interrupted with a chloramphenicolresistance $\left(\mathrm{cam}^{\mathrm{R}}\right)$ gene (Figure 1A). Two UPEC strains (C119 and CFT073) were successfully transformed with pKM208. Successful replacement of the wildtype dam gene was selected for by growth of chloramphenicol-resistant $\Delta$ dam colonies and PCR amplification of a 1323 bp product due to the $\Delta$ dam: $\mathrm{cam}^{\mathrm{R}}$ allele (Figure 1C). Further confirmation was revealed by a total loss of DNA adenine methylation and methylase-sensitive digestion among dam mutants (Figure 1E).

Microscopic observations revealed phenotypic variation in the population of dam-mutant strains: elongated bacilli or interconnected filamentous cells contributed up to $60 \%$ of the total population when compared to the shortened rods exclusively exhibited by wild-type strains (Figure 2C). Given that average length of wild type E. coli cells can vary between 1.6 and $3.9 \pm 0.9 \mu \mathrm{m}$ according to growth phase and condition (68), cell measurements were largely excluded. Despite this, filamentous cells demonstrated an estimated increase in cell length by up to eight times that of wild-type strains.

\section{Complementation of Dam Mutants}

To successfully construct the complementation plasmid pGEMdam or qnrA-containing pGEMQA, the corresponding dam (996 bp) or qnrA (1236 bp) amplicon from wild-type strains were used as inserts for cloning into the vector pGEM-T ${ }^{\circledR}$ Easy. Furthermore, plasmids were also successfully transformed into study strains (cC119 and CFT073) for further analysis. Micrographs and dam function analysis in dam complement strains reflected the successful morphological and phenotypic restoration of dam denoted by the predominance of shortened rods and regular dam methylation (Figure 2A) as displayed by paternal strains.

\section{Growth Rate Studies}

Despite exhibiting comparable spectrophotometric growth trends to cured parental strains, $\Delta$ dam mutants exhibited at least twofold reduction in actual growth rate, cell numbers, and an 
A

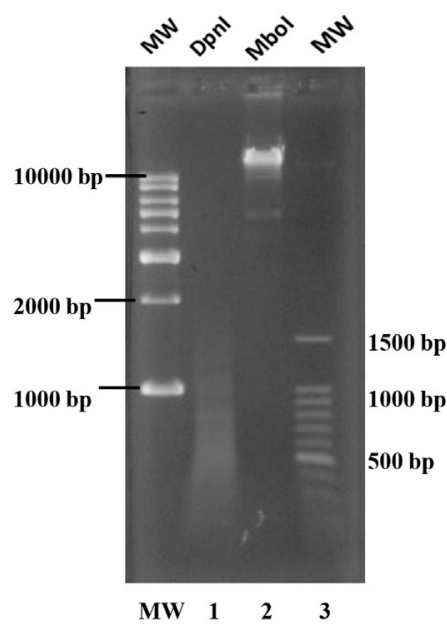

B

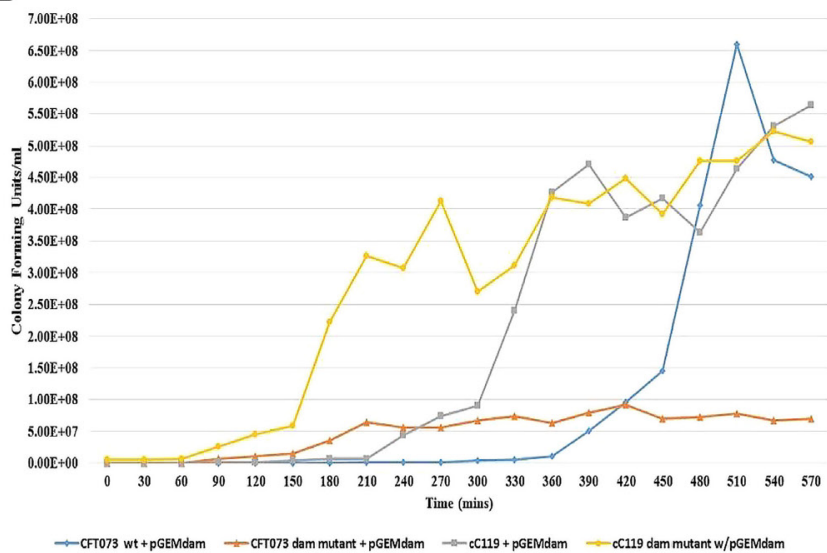

WT
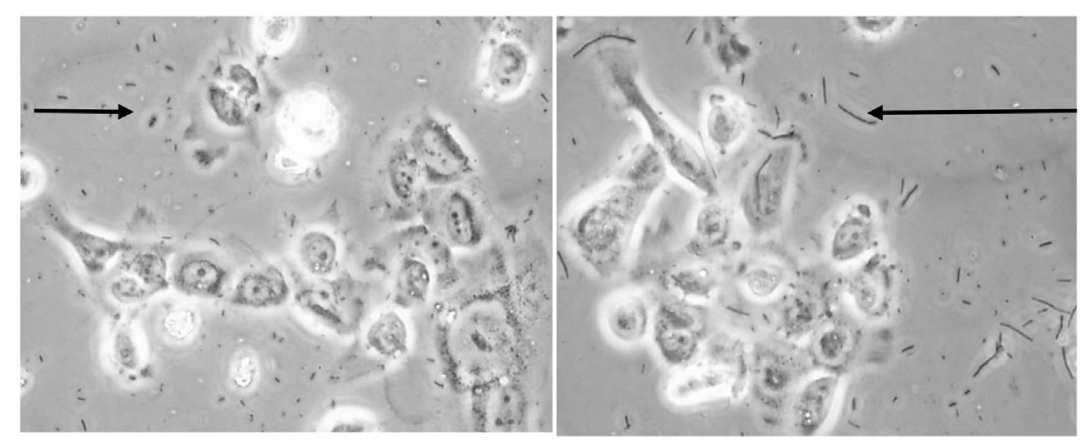

Elongated

rods

Shor
rods

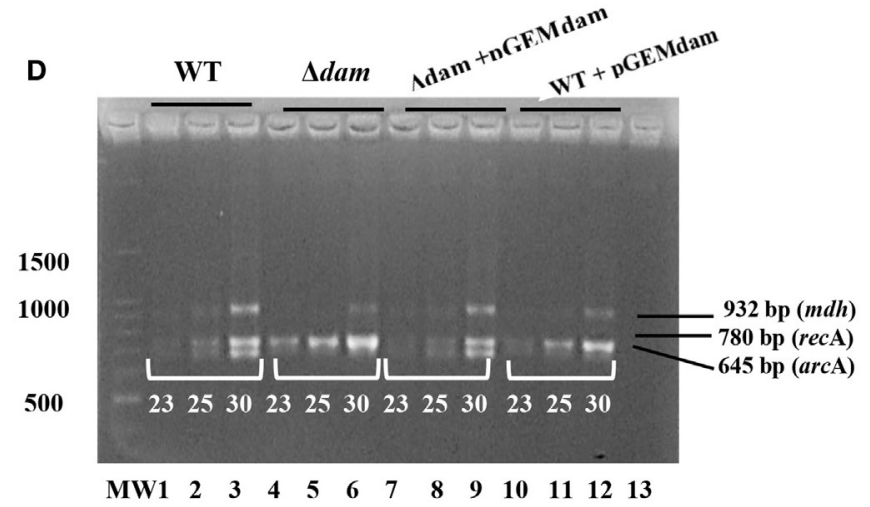

FIGURE 2 | Genetic and growth characteristics displayed by dam-complemented mutant strains of UPEC relative to wild-type. (A) Dam methylation pattern in UPEC CFT073 strain subsequent to digestion with Dpnl (lane 1) and Mbol (lane 2). The $1 \mathrm{~kb}$ plus DNA ladder (MW) is also shown. (B) Growth curve (CFU/ milliliter versus time) for dam complement UPEC strains of CFT073, CFT073 $\Delta$ dam, cC119, and cC119 $\Delta$ dam. (C) Micrographs for wild-type (WT) and dam mutant $(\Delta d a m)$ UPEC strains, illustrating the morphological occurrence of shortened- and filamentous rods, respectively. (D) Semi-quantitative RT-PCR for mdh, recA, and arcA expression at cycles 23, 25, and 30 for CFT073 (lanes 1-3), CFT073 $\Delta$ dam (lanes 4-6), CFT073 + pGEMdam (lanes 7-9), CFT073 $\Delta$ dam + pGEMdam (lanes 10-12). The 100 bp molecular marker MW (Promega, WI, USA) and negative control are shown (lane 13).

extended lag phase (90-180 min) before initiating logarithmic growth in broth cultures (Figure 1F). There were distinguishable differences in colony forming unit per milliliter over time among all four strains titred to determine viable cell counts. $\Delta$ dam mutants were significantly lower ( 4.5- to 50 -fold) in numbers when compared to wild-type counterparts at the end of log phase.
Generation time $\left(t_{\text {gen }}\right)$ derivations were $13.5 \mathrm{~min} / \mathrm{gen}$ (CFT073 wt), $32.3 \mathrm{~min} / \mathrm{gen}(\mathrm{CFT} 073 \Delta$ dam), $28.2 \mathrm{~min} / \mathrm{gen}(\mathrm{cC} 119)$, and $55.32 \mathrm{~min} / \mathrm{gen}(\mathrm{cC} 119 \Delta$ dam $)$; an approximate $50 \%$ reduction in growth rate of dam-mutant strains.

On the other hand, the restoration of the dam function by complementation for cured parental and $\Delta$ dam strains, resulted 
TABLE 3 | Antimicrobial susceptibility responses of $E$. coli wild type (wt), cured (c), dam mutant, and pGEMQA-bearing strains subjected to the sensititre substrate-in-well GNUR2F Gram-negative MIC plate test.

\begin{tabular}{|c|c|c|c|c|c|c|c|c|c|}
\hline \multirow[t]{2}{*}{ Strain } & \multicolumn{9}{|c|}{$\operatorname{MIC}(\mu \mathrm{g} / \mathrm{ml})$} \\
\hline & AMP & AUG2 & AXO & CAR & CIP & FEP & GEN & SXT & NIT \\
\hline CFT073 wt & 0 & 0 & 0 & 0 & 0 & 0 & 0 & 0 & 0 \\
\hline CFT073 $\Delta$ dam & 32 & $32 / 16$ & 0 & 64 & 0 & 0 & 0 & 0 & 0 \\
\hline CFT073 wt + pGEMQA & 32 & $32 / 16$ & 0 & 64 & 0 & 0 & 0 & 0 & 0 \\
\hline CFT073 $\Delta$ dam + pGEMQA & 32 & $32 / 16$ & 0 & 64 & 0 & 0 & 0 & $0.5 / 9.5$ & 0 \\
\hline cC119 & 32 & $32 / 16$ & 0 & 64 & 4 & 32 & 8 & 4/76 & 0 \\
\hline cC119 $\Delta$ dam & 8 & $8 / 4$ & 0 & 32 & 1 & 0 & 0 & $0.5 / 9.5$ & 0 \\
\hline cC119 wt + pGEMQA & 32 & $32 / 16$ & 0 & 64 & 4 & 4 & 0 & 4/76 & 0 \\
\hline cC119 $\Delta$ dam + pGEMQA & 32 & $32 / 16$ & 0 & 64 & 2 & 0 & 8 & $4 / 76$ & 0 \\
\hline Lo QnrA+ & 32 & $8 / 4$ & 0 & 64 & 1 & 0 & 8 & $4 / 76$ & 0 \\
\hline JM109 pGEMQA & 32 & $16 / 8$ & 0 & 64 & 0 & 0 & 0 & $4 / 76$ & 0 \\
\hline
\end{tabular}

AMP, ampicillin; AUG2 - amoxicillin/clavulanic acid; AXO, ceftriaxone; CAR, carbenicillin; CIP, ciprofloxacin; FEP, cefepime; GEN, gentamicin; SXT, trimethoprim/sulfamethoxazole, NIT, nirofurantoin.

in discernable decreases in viable count over time when compared to strains lacking the plasmid (Figure 2B). dam complement strains produced marginally higher values than wild types harboring the dam plasmid; the lag phase of plasmid-bearing wild types being as high as $330 \mathrm{~min}$. Furthermore, respective generation time derivations of $28.8,35.4,56.4$, and $26.4 \mathrm{~min} /$ gen for CFT073 + pGEMdam, CFT073 $\Delta$ dam + pGEMdam, cC119 + pGEMdam, and cC119 $\Delta$ dam + pGEMdam illustrated the role of the dam plasmid in suppressing cell division defects linked to Dam.

\section{Antimicrobial Susceptibility of pGEMQA-Positive $\Delta$ dam Mutants and Wild Type Strains}

Susceptibility responses to various antimicrobial agents varied among wild type, $\Delta d a m$ - and pGEMQA-harboring stains (Table 3). A decrease in resistance by eightfold was noted for cC119 versus cC119 $\Delta$ dam against amoxicillin/clavulanic acid, trimethoprim/sulfamethoxazole and gentamicin, and fourfold against ciprofloxacin. For CFT073 $\Delta$ dam, a 32 -fold (each) and 64-fold increase in resistance was identified against amoxicillin/ clavulanic acid, ampicillin, and carbenicillin, respectively. In contrast, the resistance response of dam mutant qnrA complement cC119 strain was similar to the parental strain, with the restoration of resistance by eightfold (trimethoprim sulfamethoxazole and gentamicin) and fourfold (amoxicillin/clavulanic acid and ampicillin). Likewise, dam-mutant qnrA complement CFT073 maintained the susceptibility pattern identified among $\Delta$ dam strains.

\section{Transcriptional Analysis}

The twofold increased expressions of recA and papIB were noted among $\Delta$ dam strains compared to cured strains of C119 and CFT073 (Figure 2D). Remarkably, results indicated up to threefold increase in expression among $\Delta$ dam strains bearing pGEMQA. With the restoration of dam through pGEMdam, $\Delta$ dam strains reverted to the original level of expression demonstrated by wild types. Parental strains harboring pGEMdam did not display alterations in recA expression. However, $\Delta$ dam strains harboring pGEMQA displayed elevated qnrA levels (twofold) relative to cured parental strain, while those with pSAMS presented up to five times elevation in papIB expression relative to parental strains. The impact of dam deficiency on the expression of $\operatorname{arcA}$ and $m d h$ was revealed by reduced expression among dam mutants by 0.5 -fold except for strain CFT073 (3x lowered $\operatorname{arcA}$ expression). papEF expression was singly identified in CFT073 + pGEMQA strains at extremely low levels. Equally, dam-mutant strains did not express dam. However, dam restoration was observed though 0.5 times lower in intensity relative to parental strains.

\section{Biofilm Analysis}

The impact of oxidative stress and quinolone presence on the formation of biofilms formed by cured parental and dam-mutant strains (with or without complementation plasmid) was examined to simulate cell aggregation intensity during infections. Overall, our findings point to greater levels of biofilm formation based on $A_{570}$ values among plasmid-free dam mutants than wild-type strains in the absence of environmental stress. (Figures 3 and 4). Box and whisker plots for biofilm formation in the presence of peroxide stress revealed the discernible positive impact of dam mutation on UPEC biofilm formation in all concentrations tested. Interestingly, all phenotypes except wild-type strains harboring pGEMdam attained elevated values at $1 \mathrm{mM}$ with dam complemented strains, exhibiting median values analogous to both mutant and cured wild type. Exposure to increasing concentrations of peroxide resulted in elevated levels of biofilm formation (up to $1 \mathrm{mM}$ for CFT073 strains), followed by a $20 \%$ gradual decrease among cC119 strains (Figures 3A,B). OD readings were notably higher for plasmidfree $\Delta d a m$ strains when compared to cured parental strains despite lower biofilm percentages. This was denoted by the general decrease up to $40 \mathrm{mM}$ notwithstanding CFT073 mutant strains' increase in biofilm formation $(p<0.001)$. Furthermore, cell aggregation detection among CFT073 was 30\% greater than cC119 strains. Dam-complemented strains of CFT073 were also shown to revert to comparable and appreciably stable levels of surface adherence as the wild-type, with increasing peroxide concentration. 
A

WT
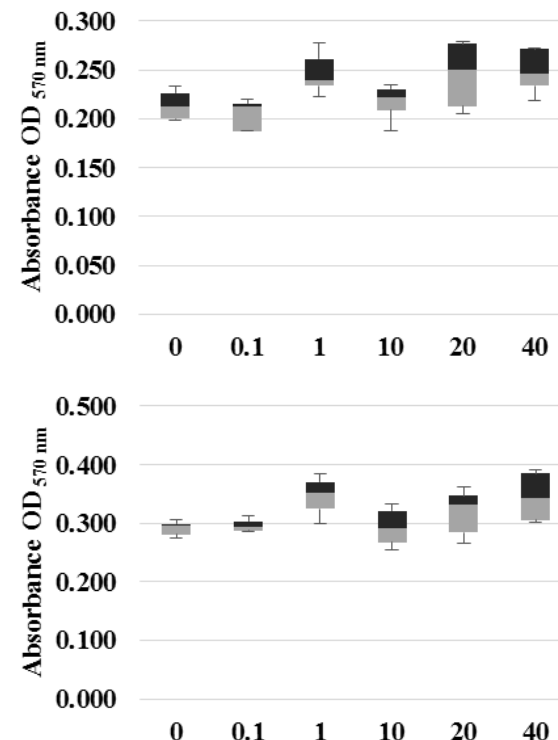

WT +

pGEMdam

$\Delta d a m$
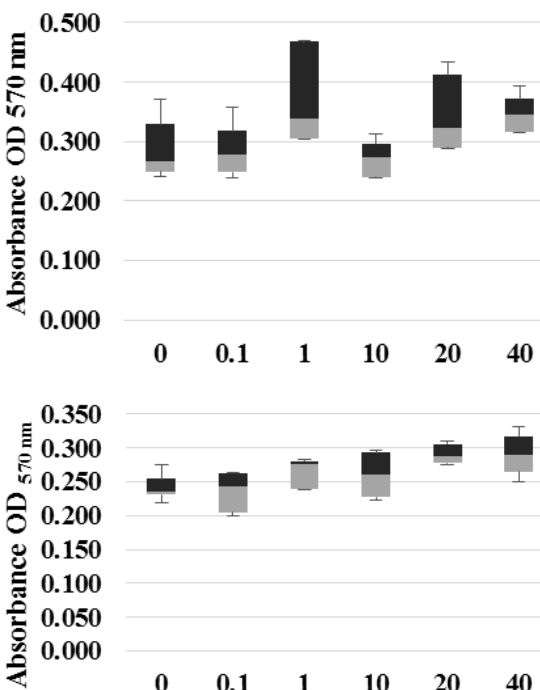

CFT073

B
cC119

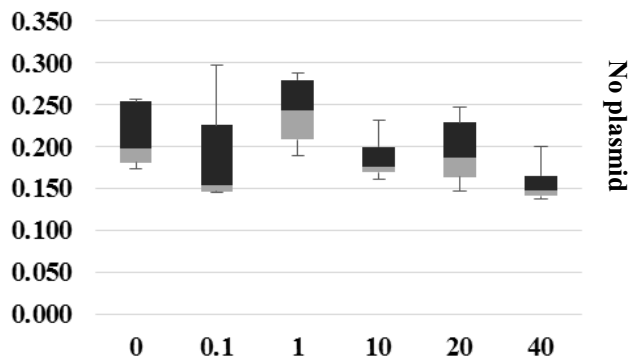

0.300

0.250

0.200

0.150

0.100

0.050

0.000

$\begin{array}{llllll}0 & 0.1 & 1 & 10 & 20 & 40\end{array}$

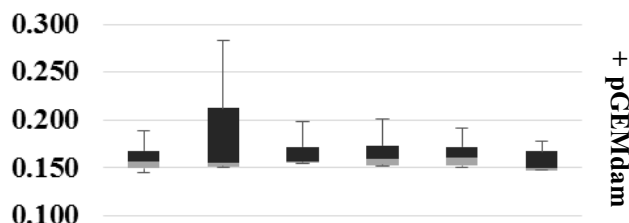

$\begin{array}{llllll}0 & 0.1 & 1 & 10 & 20 & 40\end{array}$

0.250

0.20
0.15
0.100
0.05
0.000

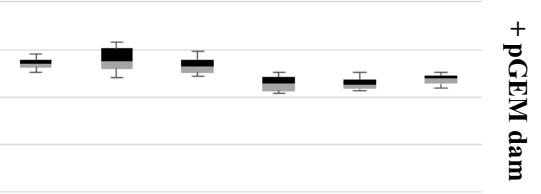

$\begin{array}{llllll}0 & 0.1 & 1 & 10 & 20 & 40\end{array}$

$\mathrm{H}_{2} \mathrm{O}_{2}$ concentration (mM)

FIGURE 3 | Distribution analysis of biofilm formation for wild type (WT), $\triangle$ dam, WT + pGEMdam, and $\triangle$ dam + pGEMdam UPEC strains of CFT073 (A) and $\mathrm{CC119}(\mathrm{B})$ in various hydrogen peroxide $\left(\mathrm{H}_{2} \mathrm{O}_{2}\right)$ concentrations.

In contrast, exposure to quinolones-favored biofilm-forming capabilities of mutant strains as median values increased from 0 to $8 \mu \mathrm{g} / \mathrm{ml} \mathrm{NAL}$ (Figures $\mathbf{4 A}, \mathbf{B}$ ). Correspondingly to oxidative stress studies, wild type strains (particularly those carrying pGEMdam) exhibited poor biofilm formation as values obtained were more skewed than mutant strains. Remarkably, the pronounced effects of plasmid pGEMQA on cured parental and dam-mutant strains were apparent since increased levels of biofilm formation were obtained despite increasing quinolone concentration.

The biofilm formation ability of plasmid-free parental strain C119 served as the baseline for quinolone pressure comparisons to $\Delta$ dam strains and statistical analysis, except where CFT073 harbored PGEMQA, since wild type phenotypes of the strain are susceptible to antimicrobial agents. Supplementation with nalidixic acid resulted in an overall inhibition, and decrease in biofilm formation as NAL concentration increased (Figures 4A,B). Notwithstanding this inhibition, proliferation among dam-mutant strains was marginally higher in contrast to wild type, notably among CFT073 mutant strains carrying pGEMQA (twofold increase at $8 \mu \mathrm{g} / \mathrm{ml} \mathrm{NAL}$ ). Furthermore, NAL resistance and biofilm formation in cC119 dam-mutant strains harboring pGEMQA 
A

cC119

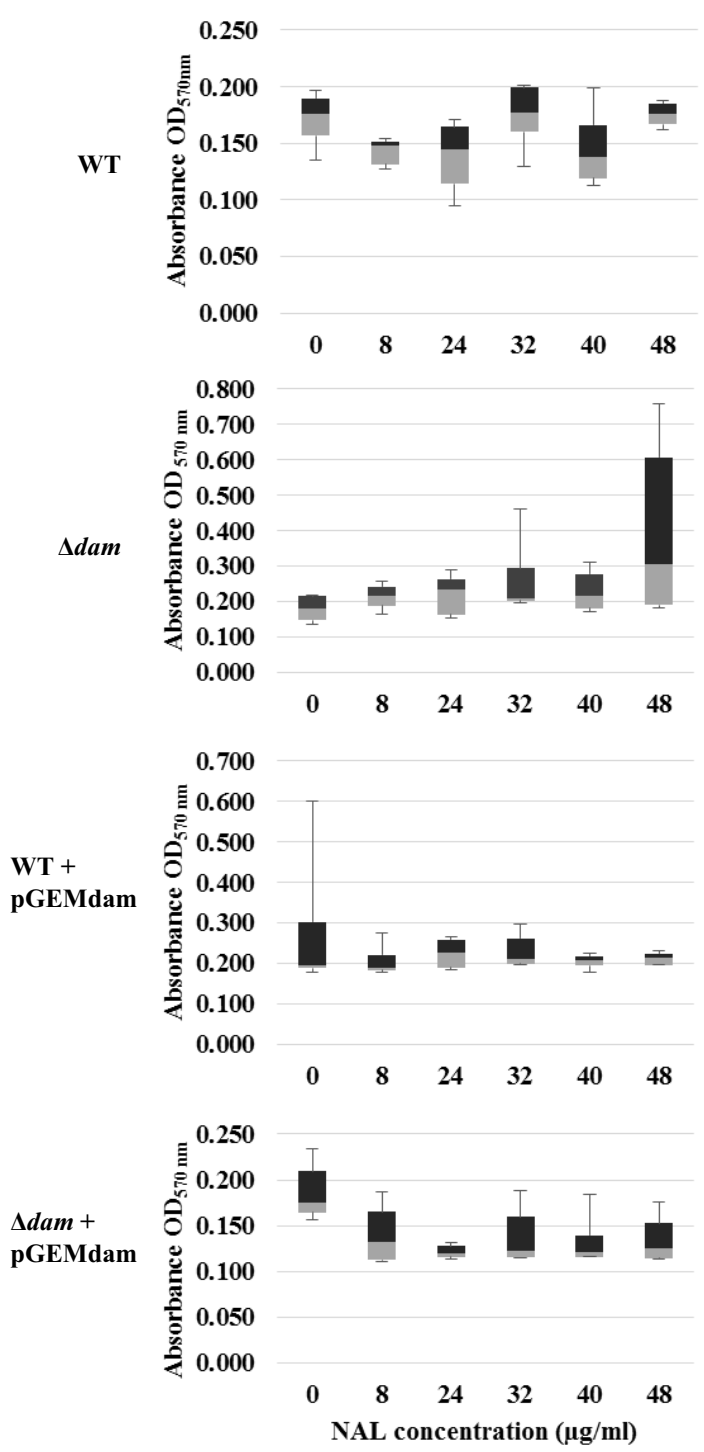

B

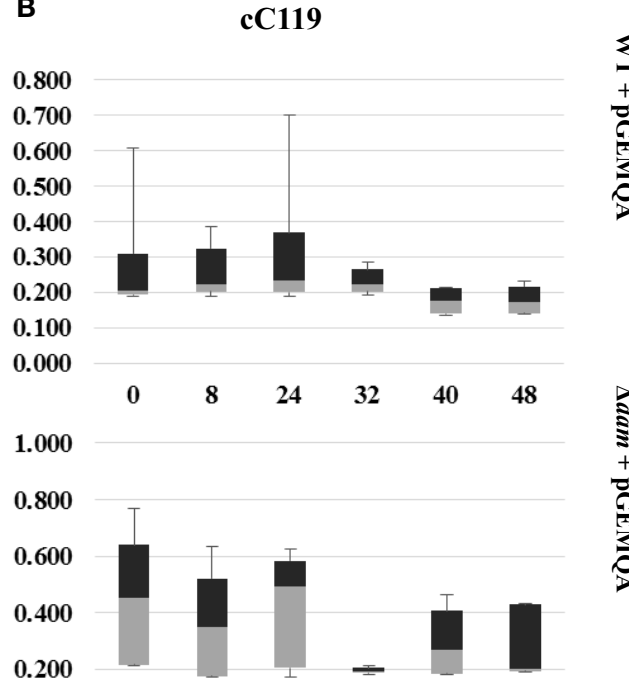

0.000

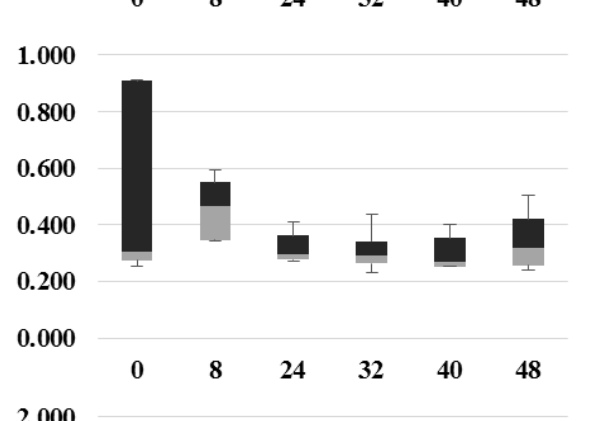

2.000

1.500

1.000

0.500

0.000

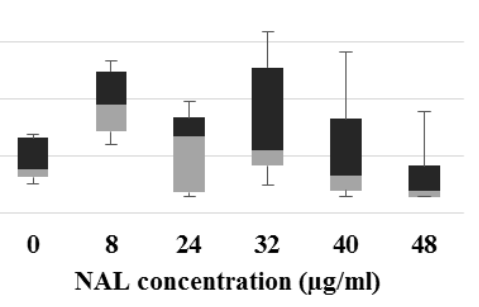

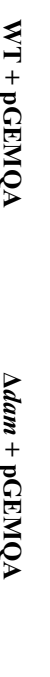

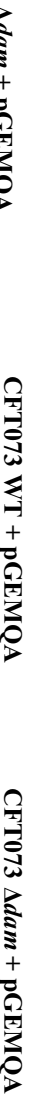

FIGURE 4 | Distribution analysis of biofilm formation for wild type (WT), $\Delta$ dam, WT + pGEMdam, $\Delta$ dam + pGEMdam, pGEMQA-harboring UPEC strains of CFT073 (A) and CC119 (B) in various peroxide and nalidixic acid (NAL) concentrations.

$(p<0.05)$ were restored to levels similar to the plasmid-free NAL-resistant parental strains. Studies with second generation quinolone, ciprofloxacin, were limited to $\mathrm{cC} 119$ for reasons indicated beforehand. Similar outcomes including the initial proliferation of plasmid-free cC119 $\Delta$ dam strain at $0 \mu \mathrm{g} / \mathrm{ml}$ $(p<0.05)$ were observed. However, steady decreases up to $5 \mu \mathrm{g} / \mathrm{ml}$ CIP were noted, notwithstanding proliferation at $1 \mu \mathrm{g} / \mathrm{ml}$. Marginally higher levels of biofilm formation were observed among $\Delta$ dam strains, steadily decreasing with an increase in CIP concentrations. Notably, mutant cells harboring $\mathrm{PGEMQA}$ exhibited fluctuations in response in comparison to steady levels of cell aggregation displayed by parental and $\Delta$ dam strains harboring pGEMdam.

\section{Role of Dam in papl-B Methylation}

papI's role in the regulation of the $\mathrm{P}$ fimbriae epigenetic switch also led explorations on whether papI-B regions were methylated and if there were discrepancies in papI expression for dam-deficient and dam-positive cells from UPEC clinical isolates. To begin examining these questions, the initial detection of $\mathrm{P}$ fimbriae via papEF (336 bp) screening was coupled to papI-papB (418 bp) detection (Figures $5 \mathbf{A}, \mathbf{B}$ ) and cloning into pCR ${ }^{\circledR} \mathrm{II}-\mathrm{TOPO} 10^{\circledR}$ to successfully produce recombinant plasmids pSAMS1 (cU115) and pSAMS2 (cC119) (Figure 5C). For further testing on the interaction of dam and papI-B, UPEC $\Delta$ dam strains and non-pathogenic control strain E. coli JM109 were successfully transformed with pSAMS, the papI-papB insert excised by EcoRI and subjected 

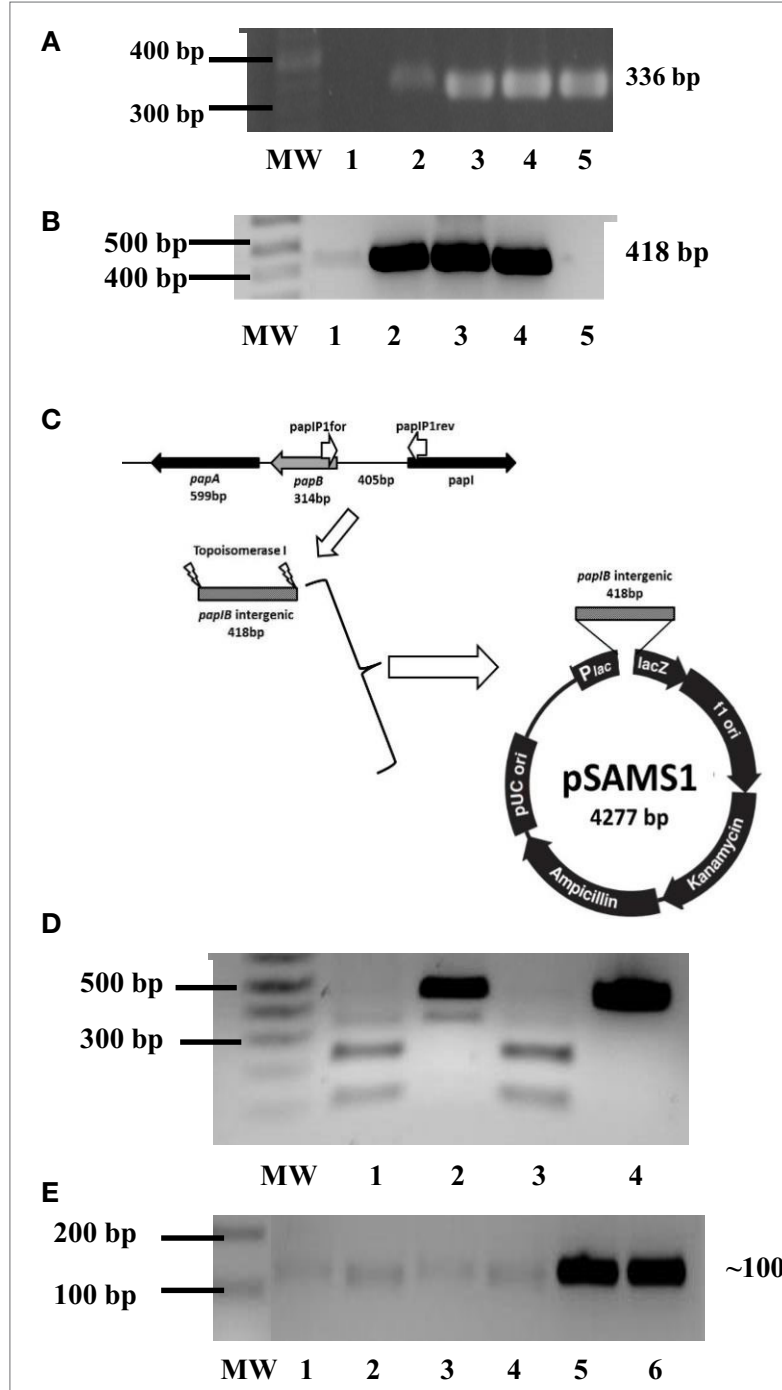

$\sim 100$ bp

FIGURE 5 | Phenotypic influence of Dam on P fimbriae. (A) PCR screening for papEF in UPEC strains cC119 (lane 4), CFT073 (lane 5), and cU155 (lane 6). The 100-bp molecular weight marker (Invitrogen), negative control and positive control (E. coli strain Lo gnr $\mathrm{A}^{+} / \mathrm{pap}_{\mathrm{EF}} \mathrm{F}^{+}$) are represented as MW, 1 and 2, respectively. (B) PCR screening for papl-papB intergenic regulatory region in UPEC strains from UPEC strains CC119 (lane 2), CFT073 (lane 3), and cU155 (lane 4). The 1-kb plus molecular marker (Invitrogen, CA, USA), negative control, and positive control (E. coli strain Lo gnr $\mathrm{A}^{+} /$papEF ${ }^{+}$) are represented as MW, 2 and 5, respectively. (C) Schematic representation of pSAMS1 recombinant plasmid containing cloned paplB insert within pCRII-TOPOII vector. (D) Dam methylation patterns for papl-B regulatory region. Sau3Al (lane 2), Mbol (lane 3), and Dpnl (lane 4) digests of pSAMS2 isolated from $\mathrm{cC} 119$ are shown. MW represents the $1 \mathrm{~kb}$ Plus molecular marker (Invitrogen). An undigested paplB fragment (lane 5) is also represented. (E) Semi-quantitative (sq) RT-PCR for papl expression in cC119 (lane 1), cC119 $\Delta$ dam (lane 2), CFT073 wild-type (lane 3) and CFT073 $\Delta$ dam (lane 4). The $1 \mathrm{~kb}$ Plus molecular marker (Invitrogen) and amplified chromosomal DNA for UPEC strains CC119 and CFT073 are shown in lanes MW, 5 and 6, respectively.

to a Dam methylation assay to reveal methylation (Figure 5D). Moreover, semi-quantitative RT-PCR used to deduce the potential influence of dam on the expression of pap-associated genes and compare papI expression in cured parental and dam mutant UPEC strains reflected an approximate twofold increase in the transcription level of the papI gene in $\Delta$ dam strains (Figure 5E).

\section{Effect of Dam on UPEC's Attachment to Mammalian Cells}

To examine the effect of Dam on UPEC's interaction with mammalian cells, the ability of dam-deficient versus damproficient UPEC cells to adhere to cultured uroepithelial cells in vitro was examined. $\Delta$ dam strains demonstrated threefold (CFT073) to fourfold higher (cC119) cell binding levels to HEK-298 cells than their parental counterpart (Table 4). Similarly, there was threefold increase in binding to HTB-9 cells for CFT073 $\Delta$ dam mutants. We also noted favorable attachment of wild-type and $\Delta$ dam strains to HTB-9 cells (relative to HEK-293) ranging from 16- to 6-fold (for $\mathrm{CC} 119$ ) to 9- to 7-fold (for CFT073), respectively.

\section{DISCUSSION}

The molecular basis of epidemiological studies serves as the most substantial tool in understanding the pathogenesis and transmission of pathogens. In this study, the dam was identified as the prime source of DNA methylation in UPEC subsequent to dam gene interruption. Successful disruption by allelic exchange results in the partial substitution of archetypical alleles with inserts on the bacterial chromosome. Moreover, attempts at dam complementation proved successful in restoration of dam function (suppression of elongated cells and cell division defect), growth rate, biofilm formation, and gene expression studies. The pleomorphic appearance of filamentous, elongated rods among $\Delta$ dam strains when compared to those of wild type origin (shortened rods) denoted phenotypic similarity among the Enterobacteriales as reported by previous studies of E. coli $\mathrm{K} 12$ (29) and EHEC OH157:O7 (26). This modification points to the impact of dam methylation on several cellular processes in related bacteria in the orders Enterobacteriales since Dam is essential to DNA replication, gene expression regulation and mismatch repair induced by the SOS regulon (69).

The SOS regulon constitutes a collective series of over 30 genes executing a myriad of biological effects following interference in cell division, DNA replication, or damage $(70,71)$. These genes (recA, lexA, sulA, polB, uvr $\mathrm{AB}, \operatorname{din} \mathrm{DF}$, etc.) dispersed around the chromosome are negatively regulated and repressed (72). Cell rescue subsequent to stress exposure by exogenous DNA damaging agents (e.g., UV irradiation, nalidixic acid, superoxides, 2-aminopurine) chiefly involves the interplay of RecA and LexA proteins required in expression of the regulon $(72,73)$. The single-stranded DNA assemblage of coprotease RecA mediates self-cleavage of LexA, the transcriptional repressor protein to activate the transcription of SOS response genes (74). Studies on the interplay of Dam with SOS regulation confirm its role as part of the recombinational repair system since deficiency results in pleiotropic changes as seen in $\Delta d a m$ cells $(75,76)$. Hence, the filamentous appearance of mutant cells are assumed to be an indirect outcome of dam deficiency, of which the SulA protein activated 
TABLE 4 | Data representing mean \pm SD of separate experiments for attachment assay of CFT073 wt, CFT073 $\Delta d a m$ mutant, cC119, and cC119 $\Delta d a m$ mutant to HEK-293 kidney and HTB-9 bladder cells.

\begin{tabular}{|c|c|c|c|c|c|c|}
\hline \multirow[t]{4}{*}{ E. coli strain } & \multicolumn{6}{|c|}{ Colony count } \\
\hline & \multicolumn{3}{|c|}{ HEK-293 } & \multicolumn{3}{|c|}{ НTB-9 } \\
\hline & Mean CFU/ml $\left(\times 10^{4}\right)$ & Mean CFU/ml $\left(\times 10^{5}\right)$ & & Mean CFU/ml $\left(\times 10^{5}\right)$ & Mean CFU/ml $\left(\times 10^{6}\right)$ & \\
\hline & Adherent & Total & $\%$ Adherent & Adherent & Total & $\%$ Adherent \\
\hline CFT073 wt & $1.55 \pm 0.35$ & $3.02 \pm 2.51$ & 5.1 & $3.02 \pm 2.51$ & $11.6 \pm 6.58$ & 2.6 \\
\hline CFT073 $\Delta$ dam & $0.55 \pm 0.05$ & $3.04 \pm 2.91$ & 1.8 & $3.04 \pm 2.91$ & $3.97 \pm 0.73$ & 7.7 \\
\hline cC119 & $5.20 \pm 0.10$ & $11.9 \pm 7.73$ & 4.4 & $11.9 \pm 7.73$ & $52.2 \pm 18.27$ & 2.3 \\
\hline cC119 $\Delta$ dam & $1.70 \pm 0$ & $4.10 \pm 2.95$ & 4.1 & $4.10 \pm 2.95$ & $15.3 \pm 10.01$ & 2.7 \\
\hline
\end{tabular}

in the latter part of SOS induction inhibited cell division and extended the period for DNA repair (74). More specifically, the inhibition of FtsZ polymerization by SulA prevents septation of cells and mutant DNA transfer to daughter cells since the absence of hemimethylated DNA at the replication fork profoundly alters initiation of chromosome replication. Post-DNA repair, SOS regulation is repressed by LexA and SulA is degraded to restore normal cell division $(71,77)$. Filamentation in response to SOS induction by DNA damaging elements of exogenous or innate immune response (polymorphonuclear leukocytes) origins may therefore serve as a means of pathogenicity as seen in the latter stage UPEC biofilm formation than singly a mechanism of survival (71).

In regards to growth rate of dam mutants, the prolonged lag phase preceding the comparable logarithmic phase trend to that of parental strains was noted and has also been described in dam mutants of Acinetobacter actinomycetemcomitans (78). The reduction in cell count among mutants points to the role of Dam methylase in initiating and coordinating chromosome DNA replication, nucleoid segregation, gene expression, and ultimately cell division. In E. coli, the replication of dnaA-dependent chromosome from the origin of replication (oriC) is minimal to lacking in the absence of complete methylation of oriC GATC sites by Dam $(79,80)$. Hemimethylated origin will remain inactive, and further prevent methylation of daughter DNA strands during DNA replication since the origin is sequestered by SeqA. SeqA sequestering represses the initiation of new DNA replication cycles, dam regulation of the initiator DnaA promoter synthesis similarly to OriC and eventually the cell cycle, as reinitiation of chromosome replication within the same cell cycle ensues. Subsequently, DNA replication initiation is uncoordinated $(81,82)$ with defects in nucleoid structure due to the inability to form compacted chromosome structure for the organization of nascent nucleoids and decatenation of topoisomerase IV $(79,82)$. Comparatively, the observation of typical logarithmic growth among $\Delta d a m$ mutants to that of the wild type, confirms non-essential role of dam expression for viability of UPEC. However, dam does trigger hypervariability mechanisms, which may also impact the activation of physiological pathways required for growth under specific conditions. This is in agreement with observations made for $\Delta$ dam mutants of E. coli and Salmonella (30).

The extended lag phase among dam mutants in vitro may occur during acclimatization of $\Delta d a m$ strains to the growth environment and is speculated to be a direct result of the absence of Dam's correlative activity in initiating synchronized chromosomal replication at oriC and the replication fork during cell growth (83). Additionally, among dam plasmid-bearing wild types, prolonged lag phases may be accountable to multicopied dam complement plasmid strains serving as seqA phenocopies despite Dam overproduction resulting in the subsequent inhibition of SeqA (84). Rasmussen et al. (85) have linked the level of Dam methylase production to growth rate. Hence, the observed delay in logarithmic growth may be accountable to the lack of GATC methylation for post-replicative mismatch repair of newly replicated DNA (80) alongside SulA activation during the SOS response (74).

In the absence of Dam methylation, post-replicative errors or chronic DNA damage may trigger homologous recombination, an event heavily relied upon by $\Delta d a m$ strains for repair subsequent to lesions, nicks or double-stranded breaks in DNA (29, $76,80)$. As reported among Salmonella exposed to stress induced environments, such contributory factors result in increased mutability with the upregulation of the SOS regulon $(86,87)$. Equally, dam mutant UPEC strains may display increased spontaneous mutation frequency and hyperrecombinogenicity (76), the latter required to repair replication forks subsequent to numerous nicks in the single strand of DNA of the growing bacterial cell (88). The hypersensitivity and hypermutability demonstrated by dam mutants to agents (2-amino purine, ultraviolet light and reactive oxygen species) causing DNA mismatch, lesions or mutations have also been associated with the endonuclease activity of the MutHLS complex (79). Reports by Chen et al. (61) and Zaleski and Piekarowicz (89) similarly indicated the increased hypersensitive nature of dam-deficient strains to DNA-damaging agents or reactive oxygen species. Furthermore, research has shown that the Agn43 outer membrane protein involved in biofilm formation in E. coli is epigenetically regulated by competitive binding between OxyR (global oxidative stress protein) and Dam. Absence of methylation within GATC sites of the antigen 43 (agn43) gene promoter region has been reported to lead to lowered growth rates and may have influenced outcomes of biofilm formation assays for this study $(90,91)$.

Biofilm formation contributes to the in vivo survival and persistence of UPEC during UTI and plays a pivotal role in the colonization of the urogenital tract (92). The production of oxidative radicals by uroepithelial cells have been reported to 
enhance UPEC fitness by the induction of DNA repair systems to combat proceeding exposures, subsequent to infection - a characteristic critical for virulence (93). Interestingly, after $24 \mathrm{~h}$ of exposure dam mutants strains displayed greater persistence rates (higher cell density) but variable responses to increases in reactive oxygen species. This may be attributed to spontaneous mutation frequencies among such strains since the oxidative stress response proteins OxyR and SoxRS (principal regulators for hydrogen peroxide detoxification) in E. coli are competitive to Dam for overlapping GATC sites in, or near promoters (94). Additionally, the negative regulation of the antigen 43 phase variable biofilm formation autotransporter boosts autoaggregation and 3D appearance (94). In the absence of $\mathrm{dam}$, the phase variation protein binding (epigenetic switch) at three GATC sites in $\operatorname{agn} 43(\mathrm{flu})$ is hampered since activation occurs subsequent to methylation (34). Contrary to expected outcomes, this should lower cell aggregation among mutant cells. However, the augmented occurrence of stress-induced mutagenesis and repair activated by upregulated SOS gene expression may account for elevated levels of biofilm formation among UPEC dam mutants, contrary to at least one report of increased sensitivity among E. coli dam mutants by Calmann and Marinus (95).

Further antimicrobial susceptibility studies conducted on cured and pGEMQA C119 parental and dam-mutant strains as well as pGEMQA transformants of CFT073 wild type and dam-mutant strains indicated variable phenotypic responses. Likewise, the capricious observation for dam-mutant strains (further enhanced with the presence of pGEMQA by up to threefold that of parental and dam complement strains) may have been a result of SOS activation triggered by quinolones inhibiting the topoisomerase IV activity $(72,82)$. Dam-mutant strains of C119 were notably altered in resistance against various classes of antimicrobial agents by as much as eightfold in comparison to parental strains. Such variability displayed among mutants could be attributed to increased mutation rates and accumulating secondary mutations during growth. The latter would be of significant survival value in the presence of increased SOS response activators (oxidative and DNA damaging stress) and for the purpose of increased biofilm structure production.

The contribution of Dam methylation to the expression and adherence of virulence factor type 1 fimbriae in UPEC to host cells is well known to have a perceptible effect (38). Equally, Dam's role in the epigenetic switch of $\mathrm{P}$ fimbriae is of significance to the pathogenicity of uropathogenic E. coli strains implicated in UTIs. Transcriptionally controlled by cooperative binding of the leucine-responsive regulatory protein (Lrp) and translocation by ancillary protein PapI, the Pap phase variation is dependent on Dam methylation along the GATC sites upstream the papBAregulatory region (80). However, it was not until Campellone et al. (26) reported on the increased adherence of EHEC dam mutants to cultured mammalian cells when compared to wild-type EHEC that it was clear the absence of Dam function somehow triggered alternate virulence pathways; in this case, negatively regulating binding to host cells. Similarly, we make the first report of this phenomenon by UPEC $\Delta$ dam strains compared to wild-type strains with the preferred adherence of mutant strains to cultured HTB-9 bladder cells. While it is clear that there are differences in attachment between dam mutant and wild-type strains, it does not preclude the involvement of other uroadhesion mechanisms which share regulatory features to pap, e.g., afimbrial adhesin, and Type 1 and S fimbriae (96). Moreover, comparable to previous findings (25), the subtle adherence exhibited by UPEC strains to cell culture models (post-1.5 h) coincides with discrepancies noted since up to $40 \%$ of UPEC isolates display no adherence to uroepithelial cells, are almost always afimbriated and thus, may not adhere when freshly isolated or cultured (7).

Furthermore, semi-quantitative RT-PCR results also reflected this variation in gene expression as there was a measurable increase in the transcription levels of the papI gene of $\Delta d a m$ versus wild-type bacteria, suggesting that the increase in fimbriae is a direct result of alteration to the transcription initiation at regulatory sites. In this case, the alteration may have been the lack of dam methylation pattern control at both distal and proximal sites within the pap regulatory DNA leading to a constant phase ON switch for expression of the operon; a finding consistent with the report by Marinus and Casedesús (34). It is hypothesized that the reversible expression of pap allows the bacteria to attach and detach from the urogenital tissues as needed. In theory this enables colonization and infection of the bladder, then subsequently the kidney, leading to cystitis and pyelonephritis, respectively (33). However, the preferential attachment of the UPEC strains to bladder cells (seen in this study) may indicate either the occurrence of variation in PapG adhesin specificity to globoseries of the tubular mucosal cells, or the associated level of pathogenicity potential for causing infection in these tissues $(17,20,21)$.

Notably, the increased expression of recA, papI, and qnrA but decreased or absent expression of $d a m, m d h, p a p \mathrm{EF}, \operatorname{arc} \mathrm{A}, g y r \mathrm{~B}$ observed among dam mutant and dam-complement strains comparative to wild-types, underscores the high level of altered phenotypes present as a result of altered gene expression. Numerous studies with RecA have indicated its role as chief regulator in SOS induction, homologous recombination mechanisms and eventual phenotypic variations by means of phenotypic switching $(72,74,88)$. In the presence of environmental changes (e.g., oxidative stress, DNA damage), the interplay between dam and recA may be integral to the altered responses of cells for adaptation. Evidence points to increased minimal level of expression of recA in dam mutants relative to wild-type strains $(88,97)$. Various studies have shown the full functional capability of methyl-directed mismatch repair in E. coli dam mutants to induce increased nucleotide base substitutions and mutagenic doublestranded breaks $(72,88)$. Such occurrences contribute to the increased mutability and hypervariation demonstrated by mutant strains $(87,98)$. Moreover, excessive recombinational events and insufficient repair of chromosome breaks in dam mutants eventually leads to cell death as shown by the non-viability of double mutants of dam recA, dam ruvA, dam polA, dam lig, and dam priA $(76,88)$.

The preferential expression and modulation of several virulence genes by dam mutants (relative to wild-type) of pathogenic Salmonella strains (36) advocates the therapeutic potential of attenuated strains as live vaccines $(33,36,47)$ and Dam inhibitors 
as antibacterial drugs $(38,46)$. Despite this background, our findings illustrating sustained viability and low level of adherence in vitro to uroepithelial cells by $\Delta$ dam UPEC strains may dampen the prospect for solitary use of Dam inhibitors or UPEC $\Delta$ dam strains as live vaccines. Further characterization and posttranscriptional and in vivo investigations for the influence of DNA adenine methylation on virulence gene regulation may reveal associated regulatory networks and their value to vital functions indispensable to pathogenicity of UPEC and other bacteria.

\section{AUTHOR CONTRIBUTIONS}

SA-MS participated in all experiments and designing of the research plan, coordinated the data analysis and contributed to

\section{REFERENCES}

1. Welch RA, Burland V, Plunkett G, Redford P, Roesch P, Rasko D, et al. Extensive mosaic structure revealed by the complete genome sequence of uropathogenic Escherichia coli. Proc Natl Acad Sci U S A (2002) 99(26):17020-4. doi:10.1073/ pnas. 252529799

2. Zalmanovici Trestioreanu A, Green H, Paul M, Yaphe J, Leibovici L. Antimicrobial agents for treating uncomplicated urinary tract infection in women. Cochrane Database Syst Rev (2010) 10:CD007182. doi:10.1002/14651858

3. Maroncle NM, Sivick KE, Brady R, Stokes F-E, Mobley HLT. Protease activity, secretion, cell entry, cytotoxicity and cellular targets of secreted autotransporter toxin of uropathogenic Escherichia coli. Infect Immun (2006) 74:6124-34. doi:10.1128/IAI.01086-06

4. Salyers AA, Whitt DD. Bacterial Pathogenesis: A Molecular Approach. 2nd ed. Washington, DC: ASM Press (2002).

5. Li K, Zhou W, Hong Y, Sacks SH, Sheerin NS. Synergy between type I fimbriae expression and C3 opsonization increases internalisation of E. coli by human tubular epithelial cells. BMC Microbiol (2009) 9:64. doi:10.1186/1471-2180-9-64

6. Johnson JR, Stell AL. Extended virulence genotypes of Escherichia coli strains from patients with urosepsis in relation to phylogeny and host compromise. J Infect Dis (2000) 18:261-72. doi:10.1086/315217

7. Miyazaki J, Ba-Thein W, Kumao T, Yasuoka MO, Asaka H, Hayshi H. Type 1, $\mathrm{P}$ and $\mathrm{S}$ fimbriae, and afimbrial adhesin I are not essential for uropathogenic Escherichia coli to adhere to and invade bladder epithelial cells. FEMS Immunol Med Microbiol (2002) 33:23-6. doi:10.1111/j.1574-695X.2002.tb00567.x

8. Blum G, Falbo V, Caprioli A, Hacker J. Gene clusters encoding the cytotoxic necrotizing factor type I, Prs-fimbriae and $\alpha$-haemolysin form the pathogenicity island II of the uropathogenic Escherichia coli strain J96. FEMS Microbiol Lett (1995) 126:189-96. doi:10.1016/0378-1097(95)00009-T

9. Hacker J. Genetic determinants coding for fimbriae and adhesins of extraintestinal Escherichia coli. Curr Top Microbiol Immunol (1990) 151:1-27.

10. High NJ, Hales BA, Jann K, Boulnois GJ. A block of urovirulence genes encoding multiple fimbriae and haemolysin in Escherichia coli O4:K12: $\mathrm{H}^{-}$. Infect Immun (1988) 56:513-7.

11. Kao J-S, Stucker DM, Warren JW, Mobley HL. Pathogenicity island sequences of pyelonephritogenic Escherichia coli CFT073 are associated with virulent uropathogenic strains. Infect Immun (1997) 65:2812-20.

12. Knapp S, Hacker J, Jarchau T, Goebel W. Large, unstable inserts in the chromosome affect virulence properties of uropathogenic Escherichia coli O6 strain 536. J Bacteriol (1986) 168:22-30.

13. Low D, David V, Lark D, Schoolnik G, Falkow S. Gene clusters governing the production of haemolysin and mannose-resistant haemagglutination are closely linked in Escherichia coli serotype O4 and O6 isolates from urinary tract infections. Infect Immun (1984) 43:353-8.

14. Swenson DL, Bukanov NO, Berg DE, Welch RA. Two pathogenicity islands in uropathogenic Escherichia coli J96: cosmid cloning and sample sequencing. Infect Immun (1996) 64:3736-43.

15. Wullt B. Erratum to "the role of P fimbriae for Escherichia coli establishment and mucosal inflammation in the human urinary tract" [Int J Antimicrob the writing of the manuscript, approved the final version, and agreed to be accountable for all aspects of the work. PB conceived and organized the study, designed the research plan and contributed to the writing of the manuscript, approved the final version, and agreed to be accountable for all aspects of the work.

\section{ACKNOWLEDGMENTS}

Financial support was obtained from an intramural grant from the Office of Graduate Studies and Research, UWI, Mona Campus, Jamaica. We express gratitude to Professor Laura Runyen-Janecky, University of Richmond, VA, USA and the Department of Basic Medical Sciences, UWI, Mona Campus, for generously facilitating the conduction of the research.

Agents 19 (2002): 522-538]. Int J Antimicrob Agents (2003) 21(6):605-21 doi:10.1016/S0924-8579(02)00103-6

16. Eto DS, Jones TA, Sundsbak JL, Mulvey MA. Integrin-mediated hostcell invasion by type I-piliated uropathogenic Escherichia coli. PLoS Pathog (2007) 3:e100. doi:10.1371/journal.ppat.0030100

17. Godaly G, Svanborg C. Urinary tract infections revisited. Kidney Int (2007) 71:721-3. doi:10.1038/sj.ki.5002170

18. Hoepelman AIM, Tuomanen EI. Consequences of microbial attachment: directing host cell functions with adhesins. Infect Immun (1992) 60:1729-33.

19. Johnson JR. Virulence factors in Escherichia coli urinary tract infection. Clin Microbiol Rev (1991) 4:80-128. doi:10.1128/CMR.4.1.80

20. Melican K, Sandoval RM, Kader A, Josefsson L, Tanner GA, Molitons BA, et al. Uropathogenic Escherichia coli $\mathrm{P}$ and type I fimbriae act in synergy in a living host to facilitate renal colonization leading to nephron obstruction. PLoS Pathog (2011) 7:e100298. doi:10.1371/journal.ppat.1001298

21. Wright KJ, Hultgren SJ. Sticky fibers and uropathogenesis: bacterial adhesins in the urinarytract. Future Microbiol(2006) 1:75-87. doi:10.2217/17460913.1.1.75

22. Holden NJ, Gally DL. Switches, cross-talks and memory in Escherichia coli adherence. J Med Microbiol (2004) 53:585-93. doi:10.1099/jmm.0.05491-0

23. Hagberg L, Jodal U, Korhonen TK, Lidin-Janson G, Lindberg U, Svanborg Eden C. Adhesion, haemagglutination, and virulence of Escherichia coli causing urinary tract infections. Infect Immun (1981) 31:564-70.

24. Kreft B, Placzek M, Dehn C, Hacker J, Schmidt G, Waseunauer G, et al. $\mathrm{S}$ fimbriae of uropathogenic Escherichia coli binding to primary human renal proximal tubular epithelial cells do not induce expression of intercellular adhesion molecule 1. Infect Immun (1995) 63:3235-8.

25. Lane MC, Mobley HL. Role of P-fimbrial mediated adherence in pyelonephritis and persistence of uropathogenic Escherichia coli (UPEC) in the mammalian kidney. Kidney Int (2007) 72:19-25. doi:10.1038/sj.ki.5002230

26. Campellone KG, Rose AJ, Løbner-Olesen A, Murphy KC, Magoun L, Brady MJ, et al. Increased adherence and catin pedestal formation by dam-deficient enterohaemorrhagic Escherichia coli O157:H7. Mol Microbiol (2007) 63:1468-81. doi:10.1111/j.1365-2958.2007.05602.x

27. Chen YT, Shu HY, Li LH, Liao TL, Wu KM, Shiau YR. Complete nucleotide sequence of pK245 a 98-kilobase plasmid conferring quinolone resistance and extended-spectrum- $\beta$-lactamase activity in a clinical Klebsiella pneumoniae isolate. Antimicrob Agents Chemother (2006) 50:3861-6. doi:10.1128/ AAC.00456-06

28. Erova TE, Pillai L, Fadl AA, Sha J, Wang S, Galindo CL, et al. DNA adenine methyltransferase influences the virulence of Aeromonas hydrophila. Infect Immun (2006) 74:410-24. doi:10.1128/IAI.74.1.410-424.2006

29. Løbner-Olesen A, Skøvgaard O, Marinus MG. Dam methylation: coordinating cellular processes. Curr Opin Microbiol (2005) 8:154-60. doi:10.1016/j. mib.2005.02.009

30. Low DA, Weyand NJ, Mahan MJ. Roles of DNA adenine methylation in regulating bacterial expression and virulence. Infect Immun (2001) 69:7197-204. doi:10.1128/IAI.69.12.7197-7204.2001

31. Fälker S, Schmidt MA, Heusipp G. DNA methylation in Yersinia enterocolitica: role of DNA adenine methyltransferase in mismatch repair and 
regulation of virulence factors. Microbiology (2005) 151:2291-9. doi:10.1099/ mic.0.27946-0

32. Ostendorf T, Cherepanov P, De Vries J, Wackernagel W. Characterization of a dam mutant of Serratia marescens and nucleotide sequence of the dam region. J Bacteriol (1999) 181:3880-5.

33. Julio SM, Heithoff DM, Provenzano D, Klose KE, Sinsheimer RL, Low DA, et al. DNA adenine methylase is essential for viability and plays a role in the pathogenesis of Yersinia pseudotuberculosis and Vibrio cholera. Infect Immun (2001) 69:7610-5. doi:10.1128/IAI.69.12.7610-7615.2001

34. Marinus MG, CasadesúsJ. Roles of DNA adenine methylation in host-pathogen interactions: mismatch, repair, transcriptional regulation, and more. FEMS Microbiol Rev (2009) 33:488-503. doi:10.1111/j.1574-6976.2008.00159.x

35. Reisenauer A, Kahng LS, McCollum S, Shapiro L. Bacterial DNA methylation: a cell cycle regulator? J Bacteriol (1999) 181:5135-9.

36. Badie G, Heithoff DM, Sinsheimer RL, Mahan MJ. Altered levels of Salmonella DNA adenine methylase are associated with defects in gene expression, motility, flagellar synthesis, and bile resistance in the pathogenic strain 14028 but not in laboratory strain LT2. J Bacteriol (2007) 189:1556-64. doi:10.1128/ JB.01580-06

37. Braaten BA, Platko JV, van der Woude MW, Simons BH, de Graaf FK, Calvo JM, et al. Leucine-responsive regulatory protein controls the expression of both the pap and fan pili operons in Escherichia coli. Proc Natl Acad Sci U S A (1992) 9:4250-4. doi:10.1073/pnas.89.10.4250

38. Casadesús J, Low D. Epigenetic gene regulation in the bacterial world. Microbiol Mol Biol Rev (2006) 70:830-56. doi:10.1128/MMBR.00016-06

39. García Del-Portillo F, Pucciarelli MG, Casadesús J. DNA adenine methylase mutants of Salmonella typhimurium show defects in protein secretion, cell invasion, and M cell cytoxicity. Proc Natl Acad Sci U S A (1999) 96:1178-83.

40. Hernday AD, Braaten BA, Low DA. The mechanism by which DNA adenine methylase and PapI activate the pap epigenetic switch. Mol Cell (2003) 12:947-57. doi:10.1016/S1097-2765(03)00383-6

41. Blyn LB, Braaten BA, Low DA. Regulation of pap pilin phase variation by a mechanism involving differential dam methylation states. EMBO J (1990) 9:4045-54.

42. Weyand NJ, Low DA. Regulation of Pap phase variation. Lrp is sufficient for the establishment of the phase OFF pap DNA methylation pattern and repression of pap transcription in vitro. J Biol Chem (2000) 275:3192-200. doi:10.1074/jbc.275.5.3192

43. van Der Woude MW, Braaten BA, Low DA. Evidence for a global regulatory control of pilus expression in Escherichia coli by Lrp and DNA methylation: model building based on analysis of pap. Mol Microbiol (1992) 6:2429-35. doi:10.1111/j.1365-2958.1992.tb01418.x

44. van der Velden AW, Baumler AJ, Tsolis RM, Heffron F. Multiple fimbrial adhesins are required for full virulence of Salmonella typhimurium in mice. Infect Immun (1998) 66:2803-8.

45. Heithoff DM, Badie G, Julio SM, Enioutina EY, Daynes RA, Sinsheimer RL, et al. In vivo-selected mutations in methyl-directed mismatch repair suppress the virulence attenuation of Salmonella dam mutant strains following intraperitoneal, but not oral, infection of naïve mice. JBacteriol (2007) 189(13):4708-17. doi:10.1128/JB.00299-07

46. Jakomin M, Chessa D, Bäumler AJ, Casadesús J. Regulation of the Salmonella enteric std fimbrial operon by DNA adenine methylation, SeqA, and HdfR. J Bacteriol (2008) 190:7406-13. doi:10.1128/JB.01136-08

47. Plumbridge J. The role of dam methylation in controlling gene expression. Biochimie (1987) 69:439-43. doi:10.1016/0300-9084(87)90081-2

48. Stephenson S, Brown PD, Holness A, Wilks M. The emergence of qnr-mediated quinolone resistance among Enterobacteriaceae in Jamaica. West Indian Med $J(2010)$ 59:241-4.

49. Stephenson S, Brown PD. Occurrence of class I integrons among uropathogenic fluoroquinolone-resistant Escherichia coli isolates in Jamaica. APMIS (2013) 121(3):226-31. doi:10.1111/j.1600-0463.2012.02960.x

50. Mobley HL, Green DM, Trifillis AL, Johnson DE, Chippendale GR, Lockatell CV, et al., editors. Pyelonephritogenic Escherichia coli and killing of cultured human renal proximal tubular epithelial cells: role of hemolysin in some strains. Infect Immun (1990) 58:1281-9.

51. Murphy KC, Campellone KG. Lambda Red-mediated recombinogenic engineering of enterohemorrhagic and enteropathogenic E. coli. BMC Mol Biol (2003) 4:11. doi:10.1186/1471-2199-4-11
52. Datsenko KA, Wanner BL. One-step inactivation of chromosomal genes in Escherichia coli K-12 using PCR products. Proc Natl Acad Sci U S A (2000) 97:6640-5. doi:10.1073/pnas.120163297

53. Blattner FR, Plunkett G, Bloch CA, Perna NT, Burland V, Riley M, et al. The complete genome sequence of Escherichia coli K-12. Science (1997) 277:1453-74. doi:10.1126/science.277.5331.1453

54. McDonald LC, Chen F-J, Lo H-J, Yin H-C, Lu P-L, Huang C-H, et al. Emergence of reduced susceptibility and resistance to fluoroquinolones in Escherichia coli in Taiwan and contributions of distinct selective pressures. Antimicrob Agents Chemother (2001) 45(11):3084-91. doi:10.1128/AAC.45.11.3084-3091.2001

55. Komp Lindgren P, Karlsson $\AA$, Hughes D. Mutation rate and evolution of fluoroquinolone resistance in Escherichia coli isolates from patients with urinary tract infections. Antimicrob Agents Chemother (2003) 47(10):3222-32.

56. Rodriguez-Siek KE, Giddings CW, Doetkott C, Johnson TJ, Fakhr MK, Nolan LK, et al. Comparison of Escherichia coli isolates implicated in human urinary tract infection and avian colibacillosis. Microbiology (2005) 151:2097-110. doi:10.1099/mic.0.27499-0

57. Beutin L, Strauch E, Zimmermann S, Kaulfuss S, Schaudinn C, Männel A, et al. Genetical and functional investigation of fliC genes encoding flagellar serotype $\mathrm{H} 4$ in wildtype strains of Escherichia coli and in a laboratory E. coli K-12 strain expressing flagellar antigen type H48. BMC Microbiol (2005) 5:4. doi:10.1186/1471-2180-5-4

58. Wirth T, Falush D, Lan R, Colles F, Mensa P, Wieler LH, et al. Sex and virulence in Escherichia coli: an evolutionary perspective. Mol Microbiol (2006) 60(5):1136-51. doi:10.1111/j.1365-2958.2006.05172.x

59. Ferreira A, Rendano L, Wiedmann M, Boor KJ. Characterization of rpoS alleles in Escherichia coli O157:H7 and in other E. coli serotypes. J Appl Microbiol (1999) 86:295-301. doi:10.1046/j.1365-2672.1999.00664.x

60. Robicsek A, Jacoby GA, Hooper DC. The worldwide emergence of plasmid mediated quinolone resistance. Lancet Infect Dis (2006) 6:629-40. doi:10.1016/ S1473-3099(06)70599-0

61. Chen L, Paulsen DB, Scruggs DW, Banes MM, Reeks BY, Lawrence ML. Alteration of DNA adenine methylase (Dam) activity in Pasteurella multocida causes increased spontaneous mutation frequency and attenuation in mice. Microbiology (2003) 149:2283-90. doi:10.1099/mic.0.26251-0

62. Matlock BC, Beringer RW, Ash DL, Page AF. Differences in Bacterial Optical Density Measurements between Spectrophotometers. Thermo Fisher Scientific Technical Note 52236. Madison, WI: Thermo Fisher Scientific (2011).

63. Chapin KC, Musgnug MC. Validation of the automated reading and incubation system with Sensititre plates for antimicrobial susceptibility testing. J Clin Microbiol (2003) 41:1951-6. doi:10.1128/JCM.41.5.1951-1956.2003

64. Hedge A, Bhat GK, Mallya S. Effect of exposure to hydrogen peroxide on the virulence of Escherichia coli. Indian J Med Microbiol (2008) 26(1):25-8. doi:10.4103/0255-0857.38853

65. Hryckowian AJ, Welch RA. RpoS contributes to resistance to phagocyte oxidase-mediated stress during urinary tract infection by Escherichia coli CFT073. mBio (2013) 4(1):e23-13. doi:10.1128/mBio.00023-13

66. Marone M, Mozzetti S, De Ritis D, Pierelli L, Scambia G. Semiquantitative RT-PCR analysis to assess the expression levels of multiple transcripts from the same sample. Biol Proced Online (2001) 3:19-25. doi:10.1251/bpo20

67. Holden N, Totsika M, Dixon L, Catherwood K, Gally DL. Regulation of P-fimbrial phase variation frequencies in Escherichia coli CFT073. Infect Immun (2007) 75:3325-34. doi:10.1128/IAI.01989-06

68. Volkmer B, Heinemann M. Condition-dependent cell volume and concentration of Escherichia coli to facilitate data conversion for systems biology modeling. PLoS One (2011) 6(7):e23126. doi:10.1371/journal.pone. 0023126

69. Marinus MG. DNA methylation and mutator genes in Escherichia coli K-12. Mutat Res (2010) 705:71-6. doi:10.1016/j.mrrev.2010.05.001

70. Heitman J, Model P. Site-specific methylases induce the SOS DNA repair response in Escherichia coli. J Bacteriol (1987) 169(7):3243-50.

71. Justice SS, Hunstad DA, Seed PC, Hultgren SJ. Filamentation by Escherichia coli subverts innate defenses during urinary tract infection. Proc Natl Acad Sci U S A (2006) 103(52):19884-9. doi:10.1073/pnas.0606329104

72. Janion C. Some aspects of the SOS response system - a critical survey. Acta Biochim Pol (2001) 48(3):599-610.

73. O'Reilly EK, Kreuzer KN. Isolation of SOS constitutive mutants of Escherichia coli.J Bacteriol(2004) 186(21):7149-60.doi:10.1128/JB.186.21.7149-7160.2004 
74. Janion C. Inducible SOS response system of DNA repair and mutagenesis in Escherichia coli. Int JBiol Sci (2008) 4(6):338-44. doi:10.7150/ijbs. 4.338

75. Riva A, Delorme M-O, Chevalier T, Guilhot N, Hénaut C, Hénaut A. Characterization of the GATC regulatory network in E. coli. BMC Genomics (2004) 5:48. doi:10.1186/1471-2164-5-48

76. Robbins-Manke JL, Zdraveski ZZ, Marinus M, Essigmann JM. Analysis of global gene expression and double-strand-break formation in DNA adenine methyltransferase- and mismatch repair-deficient Escherichia coli. J Bacteriol (2005) 187(20):7027-37. doi:10.1128/JB.187.20.7027-7037.2005

77. Kamenšek S, Podlesek Z, Gillor O, Žgur-Bertok D. Genes regulated by the Escherichia coli SOS repressor LexA exhibit heterogenous expression. BMC Microbiol (2010) 10:283. doi:10.1186/1471-2180-10-283

78. Wu H, Lippmann JE, Oza JP, Zeng M, Fives-Taylor P, Reich NO. Inactivation of DNA adenine methyltransferase alters virulence factors in Actinobacillus actinomycetemcomitans. Oral Microbiol Immunol (2006) 21:238-44. doi:10.1111/j.1399-302X.2006.00284.x

79. Marinus MG. Methylation of DNA. In: Neidhardt FC, Curtis R III, Ingraham JL, Lin ECC, Low KB, Magasanik B, et al. Escherichia coli and Salmonella: Cellular and Molecular Biology. 2nd edn. Washington, DC: ASM Press (1996). p. 782-91.

80. Wion D, Casadesus J. N6-methyl-adenine: an epigenetic signal for DNAprotein interactions. Nat Rev Microbiol (2006) 4:183-92. doi:10.1038/ nrmicro1350

81. Boye E, Løbner-Olesen A, Skarstad K. Timing of chromosomal replication in Escherichia coli. Biochim Biophys Acta (1988) 951(2-3):359-64. doi:10.1016/0167-4781(88)90107-8

82. Palmer BR, Marinus MG. The dam and dcm strains of Escherichia coli - a review. Gene (1994) 143:1-12. doi:10.1016/0378-1119(94)90597-5

83. Marinus MG, Løbner-Olesen A. DNA methylation. EcoSal Plus (2014) 6(1). doi:10.1128/ecosalplus.ESP-0003-2013

84. Løbner-Olesen A, Marinus MG, Hansen FG. Role of SeqA and Dam in Escherichia coli gene expression: a global/microarray analysis. Proc Natl Acad Sci USA (2003) 100(8):4672-7. doi:10.1073/pnas.0538053100

85. Rasmussen LJ, Marinus MG, Løbner-Olesen A. Novel growth rate control of dam gene expression in Escherichia coli. Mol Microbiol (1994) 12:631-8. doi:1 0.1111/j.1365-2958.1994.tb01050.x

86. Marinus MG, Morris NR. Biological function for 6-methyladenine residues in the DNA of Escherichia coli K12. J Mol Biol (1974) 85:309-22. doi:10.1016/0022-2836(74)90366-0

87. Ponder RG, Fonville NC, Rosenberg SM. A switch from high-fidelity to errorprone DNA double-strand break repair underlies stress-induced mutation. Mol Cell (2005) 19:791-804. doi:10.1016/j.molcel.2005.07.025
88. Marinus MG. Recombination is essential for viability of an Escherichia coli dam (DNA adenine methyltransferase) mutant. J Bacteriol (2000) 182(2) 463-8. doi:10.1128/JB.182.2.463-468.2000

89. Zaleski P, Piekarowicz A. Characterization of a dam mutant of Haemophilus influenzae Rd. Microbiology (2004) 150:3773-81. doi:10.1099/mic.0.27225-0

90. Lim HN, van Oudenaarden A. A multistep epigenetic switch enable the stable inheritance of DNA methylation states. Nat Genet (2007) 39:269-75. doi:10.1038/ng1956

91. Wallecha A, Corventi J, Munster V, van der Woude M. Phase variation of Ag43 is independent of the oxidation state of OxyR. J Bacteriol (2003) 185:2203-9. doi:10.1128/JB.185.7.2203-2209.2003

92. Costerton JW, Stewart PS, Greenberg EP. Bacterial biofilms: a common cause of persistent infections. Science (1999) 284(5418):1318-22. doi:10.1126/ science.284.5418.1318

93. Li B, Smith P, Horvath DJ Jr, Romesberg FE, Justice SS. SOS regulatory elements are essential for UPEC pathogenesis. Microbes Infect (2010) 12(8-9):662-8. doi:10.1016/j.micinf.2010.04.009

94. Chiang SM, Schellhorn HE. Regulators of oxidative stress response genes in Escherichia coli and their functional conservation in bacteria. Arch Biochem Biophys (2012) 525(2):161-9. doi:10.1016/j.abb.2012.02.007

95. Calmann MA, Marinus MG. Regulated expression of the Escherichia coli dam gene. J Bacteriol (2003) 185:5012-4. doi:10.1128/JB.185.16.5012-5014.2003

96. Giron JA, Torres AG, Freer E, Kaper JB. The flagella of enteropathogenic Escherichia coli mediate adherence to epithelial cells. Mol Microbiol (2002) 44:361-79. doi:10.1046/j.1365-2958.2002.02899.x

97. Peterson KR, Wertman KF, Mount DW, Marinus MG. Viability of Escherichia coli K-12 DNA adenine methylase (dam) mutants requires increased expression of sp in the SOS regulon. Mol Genet Genomics (1985) 201:14-9. doi:10.1007/BF00397979

98. Wyrzykowski J, Volkert MR. The Escherichia coli methyl-directed mismatch repair system repairs base pairs containing oxidative lesions. J Bacteriol (2003) 185(5):1701-4. doi:10.1128/JB.185.5.1701-1704.2003

Conflict of Interest Statement: The authors declare that the research was conducted in the absence of any commercial or financial relationships that could be construed as a potential conflict of interest.

Copyright (C) 2016 Stephenson and Brown. This is an open-access article distributed under the terms of the Creative Commons Attribution License (CC BY). The use, distribution or reproduction in other forums is permitted, provided the original author(s) or licensor are credited and that the original publication in this journal is cited, in accordance with accepted academic practice. No use, distribution or reproduction is permitted which does not comply with these terms. 